\title{
Effects of sensor response and moving average filter duration on maximum wind gust measurements
}

\author{
Amir Ali Safaei Pirooz ${ }^{\mathrm{a}, *}$, Richard G.J. Flay ${ }^{\mathrm{a}}$, Lorenzo Minola ${ }^{\mathrm{b}}$, Cesar Azorin-Molina ${ }^{\mathrm{b}, \mathrm{c}}$, Deliang Chen ${ }^{\mathrm{b}}$ \\ a Department of Mechanical Engineering, University of Auckland, Auckland, 1142, New Zealand \\ ${ }^{\mathrm{b}}$ Regional Climate Group, Department of Earth Sciences, University of Gothenburg, Gothenburg, Sweden \\ c Centro de Investigaciones Sobre Desertificación, Consejo Superior de Investigaciones Cientificas (CIDE-CSIC), Montcada, Valencia, Spain
}

\section{A R T I C L E I N F O}

Keywords

Gust duration

Wind tunnel experiment

Anemometry

Peak wind gust

Turbulence

\begin{abstract}
A B S T R A C T
The use of wind speed data recorded using different measuring equipment (i.e. anemometers with different response characteristics) and different signal-processing procedures can introduce errors in the characterisation of surface wind speeds. This study aims to assess the effects of a set of various moving average filter durations and turbulence intensities on the recorded maximum gust wind speeds. For this purpose, a series of wind-tunnel experiments was carried out on the widely-used Vaisala WAA151 cup anemometer. The variations of gust and peak factors, and turbulence intensities measured by the cup anemometer as a function of the averaging duration and turbulence intensity are presented. The wind-tunnel results are compared with values computed from a theoretical approach, namely random process and linear system theory, and the results were also validated against values reported in the literature where possible. The results show that the maximum gust wind speeds measured using large averaging durations (e.g. $3 \mathrm{~s}$ or $5 \mathrm{~s}$ ) lead to up to $25 \%-30 \%$ negative biases compared to high frequency measurements (e.g. $4 \mathrm{~Hz}$ unfiltered gust measurements). This result can strongly impact subsequent meteorological, climatological and wind engineering studies, as different gust definitions have been adopted by National Weather Services and institutions around the world. Lastly, a set of correction factors (i.e. gust factor ratios) have been proposed that allows measurements at a specific gust duration to be converted to equivalent measurements at specified particular gust durations of interest.
\end{abstract}

\section{Introduction}

Fewer wind speed trend analyses have been conducted compared to other climate variables, due to the large variability of wind on all time scales and in three-dimensional space (Azorin-Molina et al., 2014). In addition, besides the effects of instrumentation, signal processing and response characteristics of anemometers, there are various external factors, such as the surrounding environment, anemometer height, ageing of the anemometer (Pindado et al., 2012), rough weather conditions, among others, influencing long-term wind data, which make the analyses more challenging (Turner et al., 2019; Safaei Pirooz et al., 2018a; Azorin-Molina et al., 2017, 2018). For instance, towers and masts, on which the anemometers are mounted, can affect the recorded wind speed (Orlando et al., 2011; Maribo Pedersen et al., 1992; Izumi and Barad, 1970; Kaimal and Wyngaard, 1990; Farrugia and Sant, 2013; Lubitz and Michalak, 2018). It has been demonstrated that the mounting arrangement could cause the anemometer measurements to be dependent on the wind direction (Maribo Pedersen et al., 1992). Another factor affecting the measurements of cup anemometers is rough conditions, like ice around the sensor, deteriorating the performance of the cup anemometer (Bégin-Drolet et al., 2011, 2012). Using observed wind data in meteorological and climatological studies without correction can introduce significant errors and contaminate the results (Azorin-Molina et al., 2014; Turner et al., 2019; Safaei Pirooz et al., 2018a; Powell et al., 1996; Masters et al., 2010). This is particularly true for gust wind speeds, which are extremely sensitive to the anemometer response characteristics and to the duration of measurement (Miller et al., 2013; Safaei Pirooz and Flay, 2018; Holmes et al., 2014; Holmes and Ginger, 2012; Azorin-Molina et al., 2019).

Accurate knowledge on the climatology of wind gusts and gust information, including gust duration, is of great importance to various industries, such as the building industry, which needs accurate assessment of maximum load or fatigue on structures, and the wind energy industry for wind farm feasibility studies (Beljaars, 1987). The effects of gust duration on maximum gust wind speeds have been recognised by several researchers (Masters et al., 2010; Miller et al., 2013; Safaei Pirooz and Flay, 2018; Holmes et al., 2014; Holmes

\footnotetext{
* Corresponding author.

E-mail address: asaf433@aucklanduni.ac.nz (A.A. Safaei Pirooz)
} 
and Ginger, 2012; Beljaars, 1987). An obvious way of characterising wind gusts is to define a gust duration related to the width of the spike in a wind speed time series causing the extreme wind in a $T$-second interval (e.g. 600 s) (Beljaars, 1987). Despite several definitions of the gust duration, the most well-known and universally-accepted definition is "an equivalent moving average" (Holmes et al., 2014; Beljaars, 1987). The same definition has been adopted in the present paper. Before the digital era, the effective gust duration of historical gust data from chart recorders (i.e. anemographs) and analogue instruments was only a function of the anemometer response (Safaei Pirooz and Flay, 2018; Holmes et al., 2014). Since the 1990s, the World Meteorological Organisation's (WMO) 3-s moving-average gust speed definition (World Meteorological Orga, 2014) has been adopted by most National Weather Services and institutions across the world. However, the rationale behind the use of 3-s for the gust duration is rarely justified (Miller, 2007).

It was generally believed that the effective gust duration of earlier generation analogue wind-measuring systems was approximately 2-3 s, which was the basis of the 3-s gust definition in many wind-loading standards (Kwon and Kareem, 2014) and later was adopted by the WMO. However, some studies have proven that this assumption is not always valid. For instance, Kwon and Kareem (2014) using a theoretical approach demonstrated that the 3-s gust duration assumed in ASCE7-95 (7-95 and Minimum Design, 1995) to be approximately equivalent to a 1-s moving average and not 3-s. Also, the 3-s gust initially assumed in the Australian/New Zealand standard (/S1170.2 and Australia/N, 2011) was later redefined to an equivalent moving average of $0.2 \mathrm{~s}$ based on the response characteristics of the pressure-based Dines anemometer system (Miller et al., 2013; Holmes et al., 2014; Holmes and Ginger, 2012). Furthermore, Miller (2007) demonstrated that applying a 3-s moving average to the instantaneous wind speed measurements, as recommended by WMO (World Meteorological Orga, 2014), without proper knowledge of the frequency response of the measuring system, could lead to serious issues, such as considerably higher effective gust durations, which in Miller's case was $6.68 \mathrm{~s}$, over twice as long as the corresponding gust duration of the anemometer response alone (Miller, 2007). This issue can have substantial implications in many applications, such as for the design wind speeds in building codes and standards.

In addition, there are still meteorological stations where non-3-s gust durations are used; for instance, the Norwegian Meteorological Institute uses 3-s moving averages whereas the neighbour Swedish Meteorological Institute applies 2-s averages instead. Even assuming that most national meteorological agencies have adopted the 3-s gust definition, there is still an issue with the treatment of historical gust wind speed measurements as well as those that have been traditionally utilised in wind engineering for determining design wind speeds. On the other hand, it is often assumed that damaging wind gusts are those that completely cover the entire structure. Although long-duration gusts are important for large buildings and structures, in the case of smaller or light structures, short gusts can cause local damage (e.g. to windows) and it is essential that they are considered when computing wind loads. These changes in the response characteristics of instruments and signal-processing methods can be expected to result in breakpoints and discontinuities in wind speed time series (Turner et al., 2019; Safaei Pirooz et al., 2018a; Azorin-Molina et al., 2018, 2019; Masters et al., 2010).

Several gust models and formulations of the gust factor have been proposed by researchers, for example (Beljaars, 1987; Cook, 1985; Wieringa, 1973, 1976; Durst, 1960). However, there have been some issues and inconsistencies when these models were employed and applied to wind speed time series (e.g. see (Miller, 2007; Krayer and Marshall, 1992; Verkaik, 2000)). In addition, some of the studies in the literature used instruments and/or signal processing methods that are obsolete now (e.g. heavy-cup anemometers, pressure-based Dines anemometer, block averaging). Krayer and Marshall (1992) compared the gust factors for different gust durations computed from hurricane wind speed records with those proposed by Durst (1960) and Cook (1985). Discrepancies were observed between some of the compared results. Later, Miller (2007) noted that the Krayer and Marshall (1992) comparison failed to account for the fact that in hurricane and strong wind conditions, the measured values are based on an anemometer/chart recorder combination, which is expected to have an effective gust duration of 1-3 s (Miller, 2007), while the gust factor curve proposed by Durst (1960) is based on 5-s block averages, which has a considerably higher effective gust duration than the stated "5-s gust duration" term. Furthermore, regarding the same issue, Kwon and Kareem (2014) and Miller (2007) have discussed that the use of the Durst gust factor curve by ASCE7-95 (7-95 and Minimum Design, 1995) and ASCE7-05 (7-05 and Minimum Design, 2006) for converting mean wind speeds to gust wind speeds and vice versa is problematic because of the same issue, i.e. different averaging schemes and gust durations.

Recently, Shu et al. (2015) investigated the characteristics of gust factor through the analysis of wind data recorded during tropical cyclones, monsoons and thunderstorms. They demonstrated that the variation of gust factor is extremely sensitive to the mean wind speed as well as the terrain roughness and topographic features. Shu et al. (2015) also evaluated the correlation between gust factor and gust duration and showed that for tropical cyclones, the regression slope is steeper, compared to monsoon winds. Due to the fact that the time scales of thunderstorms are different from those of tropical cyclones and monsoon winds, the relationship between the gust factor of thunderstorms and gust duration could not be well represented based on monsoon and tropical cyclones time-dependence curves. Having analysed the gust factors of a very strong typhoon, Cao et al. (2015) concluded that typhoon gust factors are not considerably different from those of non-typhoon winds. Lastly, they pointed out that the characteristics of the gust factors presented in their study are based on a storm-by-storm and location-by-location basis, and more field measurement and study of strong typhoons are required to fully understand the typhoon and non-typhoon gust factors.

Verkaik (2000) compared the performance and capability of two gustiness models developed by Wieringa (1976) and Beljaars (1987), both of which assume a Gaussian distribution for the fluctuations of the turbulent wind flow, in relating gustiness to surface roughness. Both models were examined at an airport station where an old measuring system was replaced with a fast-response recorder. It was found out that both models were not able to correct for the change in the observed gust wind speeds. Beljaar's model (Beljaars, 1987) provided exposure correction factors that were $0-10 \%$ smaller than those of the Wieringa model (Wieringa, 1976) for an observation period of $1 \mathrm{~h}$. In the case of shorter observation periods, the difference was larger. Verkaik (2000) also discussed a theoretical objection against the Wieringa model resulting from applying a spectra transfer function on gusts occurring in the time domain.

The response characteristics of a wind measuring chain, comprising anemometer, data logger and any additional post-recording process, play an essential role when considering the relationship between the true wind speed and the recorded wind speed (Miller, 2007). Each of the elements in the measuring chain act as a low-pass filter (Miller, 2007; Wieringa, 1976). Often, the response and filtering of the elements in the measuring chain on the recorded wind speeds are not considered (Miller, 2007). However, these effects can be substantial. Spark (Sparks, 1997) investigated the frequency response of the UK's standard Munro Mk IV cup anemometer utilised along with several different recording systems. He demonstrated that there were considerable differences between the measuring systems such that in 
some cases, the anemometer dominated the overall response of the system and in other cases, the recording device dominated and determined the gust duration. Therefore, it is of great importance to consider the filtering effect of the measuring system. With the continuous evolution of wind measuring systems, it is essential to carry out studies that investigate the response characteristics of the new systems and compare them with the previous instruments. This enables researchers to gain a better understanding of the new gust measurements as well as of the historical records and helps them to form homogenised wind speed time series.

Prior to the development of fast-response anemometers and digital recording, it was not feasible to record high-resolution gust information. Thus, a compromise was required to measure gust with a duration that satisfy most applications (Bégin-Drolet et al., 2011). In addition, most theories used to correct the data for shorter or longer durations, are derived under ideal circumstances (e.g. Gaussian stationary turbulence), however, many extreme winds do not follow these conditions, resulting in quite large uncertainties in the corrections (Bégin-Drolet et al., 2011). For example, by analysing wind velocity data recorded during several Atlantic tropical cyclones, Balderrama et al. (2012) showed that there is a non-Gaussian behaviour in the peak factor and the skewness of velocity with increasing the turbulence intensity. In the case of slow measuring systems, the gust duration produced as a result of the filtering and sampling of the measuring chain could be equated to a moving average filter (Bégin-Drolet et al., 2011). However, nowadays with fast anemometers and high sampling frequencies, and the fact that storing data is not difficult, applying a moving average filter results in filtering and losing gust information with short durations, which, as pointed out above, are useful in many fields.

In several recent studies (Masters et al., 2010; Miller et al., 2013; Holmes et al., 2014; Holmes and Ginger, 2012; Kwon and Kareem, 2014), the response characteristics of two wind measuring systems were compared by assuming characteristic parameters for the anemometer (e.g. distance constant or time constant) and using random process and linear systems theory (Davenport, 1964) along with a spectral model (e.g. von Karman). However, in this study, wind-tunnel experiments were carried out to consider the real response characteristics of the anemometer and recording system, as opposed to assuming the distance constant and applying mathematical transfer functions to replicate the anemometer response. Furthermore, power spectral densities were obtained using wind speed time series measured in the wind tunnel, instead of employing a spectral model. In addition, several parameters, such as gust and peak factors, standard deviations and maximum wind speeds were obtained as a function of both gust duration and turbulence intensity, and errors resulting from applying the moving average filter have been quantified. For comparison and validation purposes, the wind-tunnel results from the current study have been compared with theoretical results, using the properties of the full-scale wind flow, and also with some values reported in the literature (Miller et al., 2013; Holmes and Ginger, 2012). The real frequency response of the measuring chain is considered in the wind tunnel tests and the equivalent moving average filter, corresponding to the unfiltered measurement, is reported so that the results of the current paper can be applied to other measuring systems that have a similar frequency response.

Following the above discussion, the objectives of the present study are summarised as follows:

- Quantitatively compare and validate the gust factor ratios and effects of various gust durations and turbulence intensities on different parameters obtained from wind tunnel experiments with a theoretical approach.
- Compute a set of correction factors as a function of turbulence intensity to enable gust measurements obtained with one gust duration to be converted to another specified gust duration.

- Emphasise the importance of high-resolution wind speed measurements and quantify the amount of gust information lost through applying moving average filters of various durations to recorded wind data.

- Report results so they can be applied to other measuring systems, with similar frequency response characteristics, to determine the effects of the various recording and data processing methods.

Gaining a better understanding of the order of the differences and errors that can be caused by the use of different gust duration values and turbulence intensities is essential for future studies. For example, it allows wind data time series from different regions to be compared when wind data are recorded using different measuring procedures. The non-climatic effects of gust duration changes on measured wind series can also be addressed, and actual long-term trends of peak wind gusts can be accurately estimated (Azorin-Molina et al., 2016). Also, knowing the gust factors corresponding to different gust durations and terrain categories allows one to examine the potential changes in vertical gust and mean wind speed profiles as a result of changes in the measuring system and associated gust duration. Therefore, this is of great interest for meteorologists, climatologists and the wind engineering community.

\section{Methodology}

In spite of the great development of more accurate and sophisticated wind-measurement instruments, cup anemometers still remain today as the most common and popular instruments used in measuring wind speeds at meteorological stations and in wind energy industry (Ramos-Cenzano et al., 2019; Abiven et al., 2011; Palma et al., 2008) as well as other field measurements and research works, e.g. wind speed measurements in urban areas and at pedestrian level (Sanada et al., 1980; Yoshie et al., 2007; Ohba et al., 1988; Murakami and Fujii, 1983); vertical wind speed profile and field measurements (Shu et al., 2017; Wills, 1992; He et al., 2016; Giannoulis et al., 2010); and wind flow measurements over complex terrain (Flay et al., 2019; Tan et al., 2016). In addition, almost all the available long-term wind speed time series across the world have been recorded by cup anemometers (Azorin-Molina et al., 2018; McVicar et al., 2012). The Vaisala WAA151 cup anemometer was used for the present tests. It is a light-cup anemometer with a relatively small distance constant and has been widely used in many different applications; specifications can be found in Table 1 and here https://www.vaisala. com/sites/default/files/documents/WAA151_User_Guide_in_English.pdf (last accessed July 17, 2020). The tests were carried out in the boundary-layer wind tunnel at the University of Auckland, New Zealand. This boundary-layer wind tunnel is a closed-circuit wind tunnel with two fans, a maximum wind speed of $20 \mathrm{~m} \mathrm{~s}^{-1}$, and a large cross-section of $3.6 \mathrm{~m} \times 2.5 \mathrm{~m}$ (width $\times$ height). An in-house built data logger utilising an Arduino microcontroller was used to record the output pulse rate of the Vaisala anemometer at a sampling frequency of $4 \mathrm{~Hz}$, a suitable sampling frequency for most meteorological applica-

Table 1

Specification of the cup anemometer and reference wind sensor.

\begin{tabular}{lll}
\hline & Vaisala WAA151 & Cobra \\
\hline Measuring range $\left(\mathrm{m} \mathrm{s}^{-1}\right)$ & $0.5-75$ & $2-100$ \\
Accuracy $\left(\mathrm{m} \mathrm{s}^{-1}\right)$ & \pm 0.5 & \pm 0.3 \\
Output & 14 pulses per rev & Pressure \\
Sampling Frequency $(\mathrm{Hz})$ & 4 & 1000 \\
\hline
\end{tabular}


tions according to WMO (World Meteorological Orga, 2014). The data logger measures both the number of pulses and the time between the pulses to compute the frequency of pulses over a specified time period. The performance and accuracy of the data logger has been evaluated previously and was also checked against the raw pulse output of the anemometer (Safaei Pirooz and Flay, 2018) and is known to be reliable.

\subsection{Calibration}

The cup anemometer was calibrated in the empty wind tunnel, which has a relatively low turbulence intensity of about $1 \%-1.5 \%$. The calibration was carried out according to the recommendations of ASTM D5096-02 (2017) (D5096-02 and Standard T, 2017) at wind speeds ranging from $0.5 \mathrm{~m} \mathrm{~s}^{-1}$ to $20 \mathrm{~m} \mathrm{~s}^{-1}$. The output of the anemometer (pulses $\mathrm{s}^{-1}$ ) is related to the wind speed $\left(U_{f}\right)$ using Equation (1).

$U_{f}=a R+b$,

where $R$ is the output pulse rate of the anemometer, and $a$ and $b$ are the calibration constants. By using the response curve of the anemometer to determine the time constant $(\tau)$, the distance constant $(D)$ can be obtained using Equation (2).

$D=U_{f} \tau$.

A 3D Cobra ${ }^{1}$ wind sensor was used as the reference sensor for the calibration. The Cobra sensing head is $2.6 \mathrm{~mm}$ in diameter, divided into 4 angled triangular faces, each with centrally positioned pressure taps connected to fast response pressure transducers. It is able to measure flow fields within a range of $\pm 45^{\circ}$ at frequencies of more than $2000 \mathrm{~Hz}$, making it ideal for the measurement of turbulent flow fields, including the three components of wind speed and all six Reynolds stresses through pressure measurement. The manufacturer states that it remains relatively accurate for turbulence intensities in excess of 30\%, which makes it a very commonly used instrument in wind tunnels, and ideal for the present experiment. Its only real competitor, an X-wire constant temperature anemometer can only measure up to $\pm 45^{\circ}$, and then only in one plane, as each wire responds to wind speed normal to its axis. The sampling frequency of the Cobra wind sensor was set to $1000 \mathrm{~Hz}$. The main specifications of both the cup anemometer and the reference Cobra wind sensor are summarised in Table 1 .

The calibration was performed at wind speeds ranging from $0.5 \mathrm{~m} \mathrm{~s}^{-1}$ to $20.0 \mathrm{~m} \mathrm{~s}^{-1}$. The calibration equation is given in Equation (3).

$U=0.0965 R+0.2176$,

where $R$ is the pulse rate output of the anemometer in Hz. A linear relationship, with an $R^{2}$ value of 0.999 , was achieved between the Cobra reference sensor and the WAA151 wind speeds. In addition, the distance constant obtained for the anemometer was $1.27 \pm 0.21 \mathrm{~m}$, using the recommended approach of ASTM D5096-02 (2017) (D5096-02 and Standard T, 2017).

\subsection{Wind-tunnel setup}

Turbulence-inducing elements, such as grids and blocks, were used in the wind tunnel to replicate the random fluctuations of wind in nature. The tests were conducted at various turbulence intensities and wind speeds. The incoming wind flow parameters simulated in

\footnotetext{
1 https://www.turbulentflow.com.au/Products/CobraProbe/CobraProbe.php; last accessed 17 July 2020.
}

the wind tunnel are summarised in Table 2. The values tabulated below were measured by the reference Cobra sensor.

The runs in Table 2 are sorted from the highest turbulence intensity $\left(I_{u}\right)$, i.e. Run \#1, to the lowest turbulence intensity, i.e. Run \#14. In Table 2, $u, v$ and $w$ are the three wind speed components in the $x$ (longitudinal), $y$ (lateral) and $z$ (vertical) directions, respectively.

The high turbulence intensities (i.e. Runs 1-7) broadly replicate turbulence in urban areas (Terrain Categories 3 and 4 (/S1170.2 and Australia/N, 2011)), and low turbulence intensities (Runs 8-14) are similar to those of exposed open-country and sea surface terrains (Terrain Categories 1 and 2 (/S1170.2 and Australia/N, 2011)). However, it should be noted that the turbulence integral length scales $(\lambda)$ inside the wind tunnel are smaller than those of the atmospheric boundary layer (ABL) because of the presence of the wind tunnel walls that limit the size of the eddies. To address this shortcoming (i.e. smaller $\lambda$ in the wind tunnel compared to the $\mathrm{ABL}$ ), a theoretical approach has also been employed (Section 2.3) where the corresponding full-scale turbulence integral length scales were used to compute expected gust factors $(G F)$ and other parameters, and to compare them with the wind-tunnel results. The turbulence integral length scales obtained in the wind tunnel (WT $\lambda$ ) and the corresponding full-scale length scales (FS $\lambda$ ) at $10-\mathrm{m}$ height (Cook, 1985) (based on the turbulence intensity) are also given in Table 2.

\subsection{Analyses}

Random process and linear system theory (Davenport, 1964) can be used to predict the wind gust factors $(G F)$ recorded by different types of anemometers in a turbulent wind of known intensity and spectral density. In addition, the effects of a moving average filter on the gust factor can be investigated using this theory. Davenport (1964) defined the mean GF occurring over some time period $T$ as defined in Equation (4).

$G F=\frac{\widehat{U}}{\bar{U}}=1+g \frac{\sigma_{u}}{\bar{U}}$

where, $\hat{U}$ is the gust speed, $g$ is a peak factor, $\sigma_{u}$ is the standard deviation of the along-wind speed fluctuations about the mean wind speed during period $T$, and $\bar{U}$ is the mean speed. $g$ can be calculated using the formula for Gaussian random processes (Davenport, 1964) (Equation (5)),

$g=\sqrt{2 \ln (v T)}+\frac{0.5772}{\sqrt{2 \ln (v T)}}$,

Table 2

Parameters of test conditions measured by the reference Cobra sensor, along with full-scale $\lambda$ (Cook, 1985).

\begin{tabular}{llllllll}
\hline $\begin{array}{l}\text { Run } \\
\#\end{array}$ & $\begin{array}{l}\text { Speed }(\mathrm{m} \\
\left.\mathrm{s}^{-1}\right)\end{array}$ & $\begin{array}{l}u(\mathrm{~m} \\
\left.\mathrm{s}^{-1}\right)\end{array}$ & $\begin{array}{l}v(\mathrm{~m} \\
\left.\mathrm{s}^{-1}\right)\end{array}$ & $\begin{array}{l}w(\mathrm{~m} \\
\left.\mathrm{s}^{-1}\right)\end{array}$ & $\begin{array}{l}\boldsymbol{I}_{\boldsymbol{u}} \\
(\%)\end{array}$ & $\begin{array}{l}\text { WT } \lambda \\
(\mathrm{m})\end{array}$ & $\begin{array}{l}\mathrm{FS} \lambda \\
(\mathrm{m})\end{array}$ \\
\hline 1 & 11.15 & 10.13 & 2.81 & -1.31 & 36.7 & 0.097 & 53 \\
2 & 3.97 & 3.64 & 0.07 & -0.34 & 33.3 & 0.132 & 53 \\
3 & 10.04 & 9.20 & 0.14 & -0.96 & 32.4 & 0.125 & 54 \\
4 & 6.18 & 5.72 & 0.19 & -0.60 & 29.9 & 0.163 & 58 \\
5 & 3.18 & 3.01 & 0.10 & -0.23 & 26.6 & 0.165 & 59 \\
6 & 14.93 & 13.76 & 0.65 & -1.51 & 26.2 & 0.111 & 63 \\
7 & 8.24 & 7.81 & 0.30 & -0.67 & 25.6 & 0.162 & 65 \\
8 & 3.10 & 3.01 & 0.07 & -0.20 & 20.0 & 0.206 & 68 \\
9 & 7.72 & 7.49 & 0.15 & -0.52 & 19.7 & 0.184 & 68 \\
10 & 7.68 & 7.55 & 0.39 & -0.57 & 13.4 & 0.200 & 70 \\
11 & 3.10 & 3.05 & 0.15 & -0.22 & 13.2 & 0.230 & 75 \\
12 & 7.75 & 7.66 & 0.25 & -0.56 & 11.1 & 0.251 & 80 \\
13 & 9.34 & 9.20 & 0.51 & -0.65 & 11.0 & 0.272 & 80 \\
14 & 3.09 & 3.06 & 0.08 & -0.22 & 11.0 & 0.302 & 80 \\
\hline
\end{tabular}


where $v$ is the cycling rate, which is a characteristic frequency, representing an average frequency of a random process, and can be utilised for estimating the expected peak values of the process (Equation (5)) (Holmes and Ginger, 2012) and is computed using Equation (6).

$v^{2}=\frac{\int_{0}^{\infty} f^{2} S_{u}(f) d f}{\int_{0}^{\infty} S_{u}(f) d f}$,

where $f$ is frequency and $\operatorname{Su}(f)$ is the power spectral density of the longitudinal velocity component. The standard deviation, $\sigma_{u}$, is calculated using Equation (7).

$\sigma_{u}^{2}=\int_{0}^{\infty} S_{u}(f) d f$

In this study, the power spectral density $S u(f)$ was obtained from the wind-tunnel measurements, and then, by substituting the spectra into the above equations, the peak factor and gust factor were calculated.

In order to be able to quantify the effect of gust duration, a parameter $(\varepsilon)$ was defined (Equation (8)), which gives the difference in a measured parameter by the anemometer (e.g. $G F, g, \sigma_{u}, I_{u}$ ) at two different gust durations. The percent error $(\varepsilon)$ is defined in Equation (8). The terms "error" and "bias" in this paper have been used to address the "difference" between the unfiltered measurements and filtered (i.e. applying moving average) values.

$\varepsilon=\frac{\phi_{d 1}-\phi_{d 2}}{\phi_{d 1}} \times 100$,

where $\phi$ is the parameter of the interest, and $d 1$ and $d 2$ indicate the gust durations. For example, for comparing the results of 2-s and 3-s gust durations $d_{1}=2 s$ and $d_{2}=3 s$.

Another important and practical factor is defined as the ratio between the gust factors for different gust durations, called gust factor ratio $(R)$, expressed in Equation (9).

$R=\frac{G F_{d 1}}{G F_{d 2}}$,

where, $d 1$ and $d 2$ are shorter and longer gust durations, respectively. This ratio can be used to convert gust measurements with a specific gust duration to equivalent gust measurements at particular gust durations of interest. This ratio plays an essential role in eliminating breakpoints in wind-speed time series caused by changes in the instrumentation and signal processing.

Holmes and Ginger (2012) (Holmes and Ginger, 2012) and Miller et al. (2013) (Miller et al., 2013) compared the response characteristics of Synchrotac cup anemometer and the Dines pressure anemometer using random process and linear system theory. They proposed correction factors for converting 0.2-s gust measurements from the Dines to 3-s gust measurements of the cup anemometer. Their results have been compared with the results of the present study.

Here, following Holmes and Ginger (2012) (Holmes and Ginger, 2012) and Miller et al. (2013) (Miller et al., 2013), a theoretical approach, based on random process and linear system theory (Davenport, 1964), was also utilised to compare $\varepsilon$ and $R$ obtained from the wind-tunnel tests and the theory. For this purpose, the response characteristics of the cup anemometer to wind gusts were taken into account by utilising a transfer function $\left(|H(f)|^{2}\right.$ ) (whose details are described below) and multiplying the power spectral density by $|H(f)|^{2}$ (Miller et al., 2013; Holmes and Ginger, 2012).

For this method, any appropriate model for the power spectral density can be used. In the present study the von Karman spectrum was used, which is written as in Equation (10).

$\frac{f S(f)}{\sigma_{u}^{2}}=\frac{4\left(\frac{f \lambda}{\bar{U}}\right)}{\left[1+70.8\left(\frac{f \lambda}{\bar{U}}\right)^{2}\right]^{5 / 6}}$.

To account for the filtering of wind gust measurements caused by the response characteristics of the cup anemometer and also by the signal processing, the wind spectrum Equation (10) must be multiplied by $|H(f)|^{2}$. Thus, Equations (6) and (7) become Equations (11a) and (11b), respectively.

$v^{2}=\frac{\int_{0}^{\infty} f^{2} S_{u}(f)|H(f)|^{2} d f}{\int_{0}^{\infty} S_{u}(f)|H(f)|^{2} d f}$,

$\sigma_{u}^{2}=\int_{0}^{\infty} S_{u}(f)|H(f)|^{2} d f$

$|H(f)|^{2}$ is defined in Equation (12) and comprises three terms.

$|\mathrm{Hf}| 2=|\mathrm{H} 1 \mathrm{f}| 2 .|\mathrm{H} 2 \mathrm{f}| 2 .|\mathrm{H} 3 \mathrm{f}| 2$

$\left|H_{1}(f)\right|^{2}$ accounts for the filtering of the power spectral density at low frequencies resulting from computing the mean wind speed over a non-infinite time period $T$ (Miller et al., 2013).

$\left|H_{1}(f)\right|^{2}=1-\left[\frac{\sin (T \pi f)}{T \pi f}\right]^{2}$

The transfer function that accounts for the effect of the distance constant $(D)$ of a cup anemometer is given in Equation (14),

$\left|H_{2}(f)\right|^{2}=\frac{1}{1+\left(\frac{2 \pi f D}{\bar{U}}\right)^{2}}$.

Lastly, the effect of a moving average filter on the wind signal is accounted for by applying Equation (15).

$\left|H_{3}(f)\right|^{2}=\left[\frac{\sin (\tau \pi f)}{\tau \pi f}\right]^{2}$

where $\tau$ is the moving average period (i.e. gust duration).

In this study, different gust parameters have been determined for various gust durations including $1 \mathrm{~s}, 2 \mathrm{~s}, 3 \mathrm{~s}$ and $5 \mathrm{~s}$. These gust durations are compared with raw measurements (i.e. the $4 \mathrm{~Hz}$ sampled wind speeds). The raw measurements and their corresponding gust durations are only a function of the anemometer and data-logger response characteristics. In the theoretical approach, the raw measurement data was replicated by neglecting $\left|H_{3}(f)\right|^{2}$ (since there was no moving average used) and by considering only the sampling duration effect $\left(\left|H_{1}(f)\right|^{2}\right.$ ) and the anemometer response characteristic (i.e. $D,\left|H_{2}(f)\right|^{2}$ ). In the theoretical method, the wind gust parameters were obtained in the following conditions. A wind speed range of $20.0 \mathrm{~m} \mathrm{~s}^{-1}$ to $50.0 \mathrm{~m} \mathrm{~s}^{-1}$, the same turbulence intensities as the wind tunnel tests, and the full-scale length scales tabulated in Table 2. For the theoretical approach, at each turbulence intensity, the parameters were calculated for various wind speeds ranging from $20.0 \mathrm{~m} \mathrm{~s}^{-1}$ to $50.0 \mathrm{~m} \mathrm{~s}^{-1}$, and the averages of the parameters are presented and discussed in the following section.

\section{Results and discussion}

\subsection{Comparisons and validation}

In the theoretical approach, hereafter referred to as full-scale (or FS, Theory FS), the same turbulence intensities as the wind tunnel 
(WT) tests (Table 2) were used. Although the numerical values of turbulence intensities of the approach flow are the same in both WT and FS, due to the fact that in the WT the generated turbulence and vortices are at higher frequencies and $\lambda$ is smaller, the WT spectrum has much of its energy at higher frequencies compared to the FS spectrum, as illustrated in Fig. 1. Note that in Fig. 1, the FS and WT von Karman power spectral densities are normalised by the respective squares of the mean velocities (see Equation (16)).

Normalised Spectrum $=\frac{f S(f)}{\bar{U}^{2}}$.

The area under each graph is equal to the turbulence intensity squared $\left(I_{u}^{2}\right)$, as long as the abscissa is natural-log scale. Therefore,

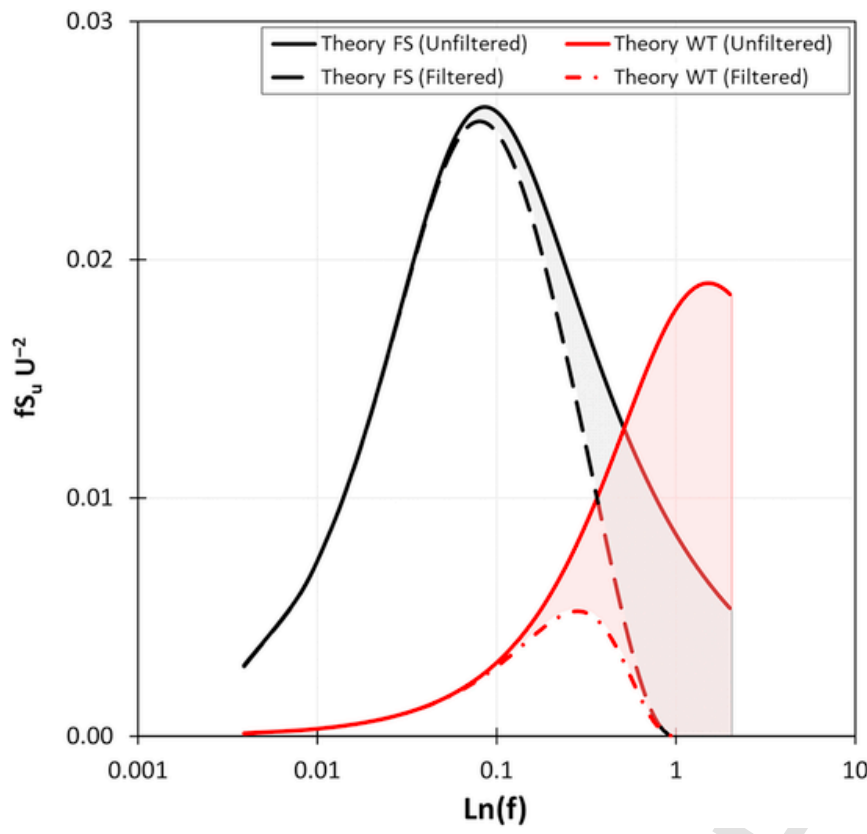

Fig. 1. Comparison of normalised von Karman spectra for full- and wind-tunnel scale turbulence. The effect of applying a 1-s moving average filter on the spectra are also shown. The dotted and hatched areas show the differences between the raw and filtered measurements for the FS and WT spectra, respectively.

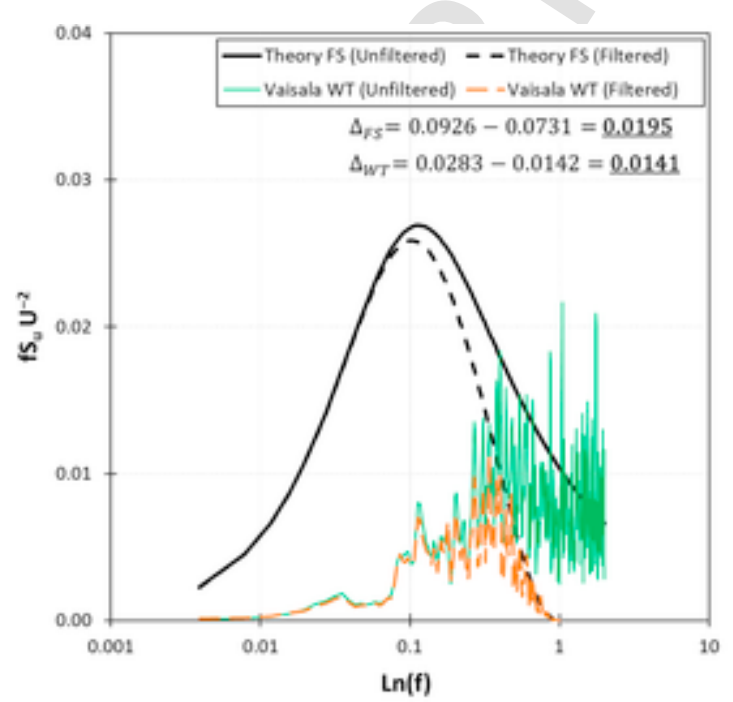

(a) to calculate the area under the normalised spectrum, Equation (16) is integrated with respect to $\operatorname{Ln} f$.

When placing a cup anemometer, a relatively slow-response wind sensor, in a wind tunnel flow with a same $I_{u}$ as a full-scale flow (determined say from a hot-wire anemometer), the cup anemometer measures a smaller $I_{u}$ compared to what it would measure in the field, because of the high-frequency fluctuations in the wind tunnel, which a cup anemometer is not capable of measuring. However, in the ABL, the broadband turbulence contains both low and high frequency turbulence, resulting in higher $I_{u}$ measured by a cup anemometer. This becomes more pronounced when the cup anemometer sampling frequency is high. At high sampling frequencies, the high-frequency fluctuations can be captured (subject to the distance-constant of the anemometer). Thus, applying a moving average filter to such a wind tunnel time series would result in a larger area of the spectrum being removed compared to what would be removed from the full-scale broadband spectrum.

However, in the case of the present cup anemometer measurements, the sampling frequency is relatively low, in the range of $1-4 \mathrm{~Hz}$. Therefore, as shown in Fig. 1, the very high frequency fluctuations cannot be measured in both FS and WT. Consequently, when a moving-average filter is applied to such wind speed time series, an approximately similar area of each spectrum is removed from both the FS and WT measurements. This is shown in Fig. 1 by the grey and pink dotted and hatched areas, which are the differences between the raw and filtered (1-s moving average) measurements $\left(=\Delta I_{u}^{2}\right)$. As can be seen, the areas are approximately similar.

For two cases of high and low turbulence intensities (Runs 2 and 14 , respectively) the normalised spectra (raw and 1-s moving-averaged) obtained from the wind tunnel and corresponding FS measurements, with $\lambda$ of $53 \mathrm{~m}$ and $80 \mathrm{~m}$ (high and low $I_{u}$, respectively), are shown in Fig. 2. As explained in Section 2.3, in the theoretical method, the von Karman spectrum was multiplied by the transfer functions, but to replicate the raw measurements in the theoretical approach, $\left|H_{3}(f)\right|^{2}$ was neglected. For these two cases, the reduction in the areas under the normalised power spectral densities resulting from applying a 1-s moving average filter to both the FS and WT measurements is also shown in Fig. 2. It equals the difference between the squared turbulence intensities (i.e. area $=I_{u}^{2}$ ) of the unfiltered and filtered data $\left(\Delta=\left(\boldsymbol{I}_{\boldsymbol{u}}^{2}\right)_{\text {unfiltered }}-\left(\boldsymbol{I}_{\boldsymbol{u}}^{2}\right)_{\text {filtered }}\right)$. As can be seen, the magnitudes of

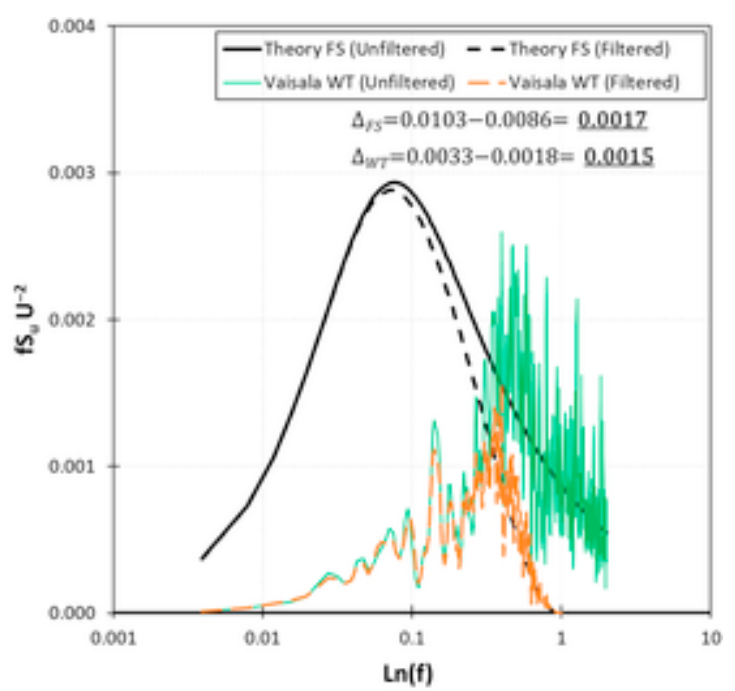

(b)

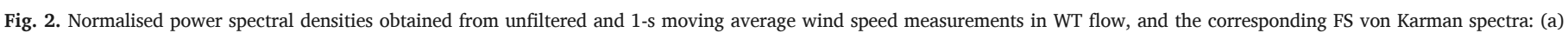
High turbulence intensity of $33 \%$ ( $\lambda=53 \mathrm{~m}$ in FS); (b) Low turbulence intensity of $11 \%(\lambda=80 \mathrm{~m}$ in FS). The magnitudes of the reductions in the respective areas ( $\Delta$ ) are also shown. 
the area reduction of FS and WT measurements, from applying the moving-average filter are approximately similar. It should be noted that the term "unfiltered" used in the present paper means that no moving-average filter was applied to the measured signal, and the gust duration is only a function of the response characteristic of the measuring chain, including the cup anemometer and the fast-response Arduino-based data logger.

As mentioned above and as can be seen in Fig. 2, the cup anemometer in the wind tunnel measures lower turbulence intensities compared to what it would measure in FS broadband turbulence, due to the relatively larger contribution from high-frequency fluctuations and the smaller turbulence integral length scale in the wind tunnel. However, the area under the spectra that is removed by applying the same 1-s moving average filter is almost equal for both the WT and FS measurements. To quantitatively investigate the magnitude of the turbulence intensities being removed by applying a moving average filter with different durations, the results from applying the same moving average filter to three turbulence conditions, namely high (\#2), medium (\#8) and low (\#14), are shown in Fig. 3. The difference in $I_{u}$ for a given filter duration compared to a 1-s longer moving filter duration is defined by Equation (17).

$$
\text { Diff }=\left(I_{u}\right)_{d_{i}}-\left(I_{u}\right)_{d_{i-1}}, \quad\left\{\begin{array}{c}
i=1,2,3,5 \\
d_{0}=\text { raw measurement }(4 \mathrm{~Hz})
\end{array}\right.
$$

As illustrated in Fig. 3, the values of the turbulence intensities in FS (black dashed lines) are about two times greater than the WT values (solid black lines). However, it should be noted that the trends of reducing turbulence intensity with an increase in the gust duration, are almost identical for both the FS and WT flows. Also, it can be seen in Fig. 3 that the amount of turbulence intensity reduction from increasing the gust duration (i.e. red dashed and solid lines) is very similar for both the FS and WT results, with differences being less than $0.5 \%$. The largest difference evident is for the high-turbulence case (Run 2), where the WT and FS results differ by up to $1.5 \%$ for the 1 -s and 5 -s durations.

According to Equation (4), another important parameter affecting the gust factor value is the peak factor. The peak factor (Equation (5)) is a function of the sampling time (T) and cycling rate (Equation (6)). $T$ was assumed to be the same (i.e. $600 \mathrm{~s}$ ) for both the wind tunnel data and the theory, thus only the difference in the cycling rate between

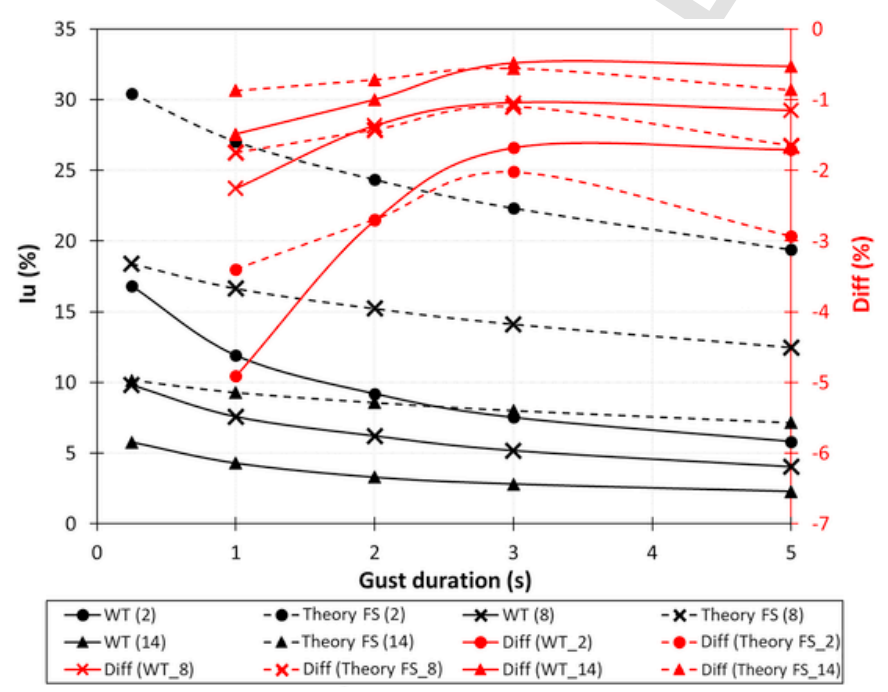

Fig. 3. Comparison of the turbulence intensity values $\left(I_{u}\right)$ and differences (Diff) for a range of filter durations obtained from the WT tests, with the theoretical approach (FS) for three different turbulence intensities, namely 33\% (Run \#2), 20\% (Run \#8) and 11\% (Run \#14). the wind tunnel and theory could cause a difference in the final peak factor values computed from either approach.

Peak factor values for the three turbulence levels obtained from the WT measurements and the corresponding FS spectra, along with the differences (Equation (8)) are shown in Fig. 4. As it is evident, there is a consistent difference $(\Delta)$ between the WT and the theoretical FS results for all the gust durations. The differences range from $4 \%$ to $12 \%$. Again, similar trends (red lines) can be seen in the reduction in the peak factor due to an increase in the gust duration for the WT and the theoretical FS results. It is also noteworthy that the peak factor, unlike gust factor, is less sensitive to the turbulence intensity of the incoming wind. However, its value decreases quite considerably with an increase in the gust (moving average) duration. As shown in Fig. 4, for the raw measurement (i.e. $4 \mathrm{~Hz}$ ) and shorter gust durations, the computed peak factors for the cup anemometer are about 3.65 for the wind tunnel flow and 3.52 from theoretical approaches, all of which agree well with peak factors reported in (Holmes et al., 2014; Deaves and Harris, 1978; Holmes, 2015). However, as the gust duration increases, the peak factor decreases monotonically. The errors in both the high and low turbulence intensities are about the same, reaching a maximum of $14 \%$ for the WT and $16 \%$ for the FS for a 5-s gust duration.

Considering that the peak factors for both the FS and WT are approximately similar (4\%-12\% difference), and that the turbulence intensities of the FS flows are much higher than those from the WT flows, then according to Equation (4), the FS gust factors should be higher than the gust factors obtained from the WT experiment. The FS and WT gust factor values are compared in Fig. 5(a) for three different turbulence intensities. As can be seen, the theoretical FS (dashed lines) values are higher than the WT (solid lines) gust factors, as expected.

However, it should be noted that the main purpose of this study is to investigate the magnitude of the changes in the gust factors resulting from applying moving average filters of different durations (i.e. error and gust factor ratio, Equations (8) and (9), respectively). Thus, the absolute values of the gust factors are of secondary interest. The trend of gust factor reduction from gust duration increase in both the FS and WT results are quite similar as shown in Fig. 5(a). Consequently, the FS and WT gust factor ratios (Equation (9)) are comparable. By way of example, one case is illustrated in Fig. 5(a) $a$ and $a_{1}$ are the ratios between the 2-s gust duration and the raw measurements of FS and WT, respectively, and as is evident, the two values from the WT data and the FS theory are almost the same.

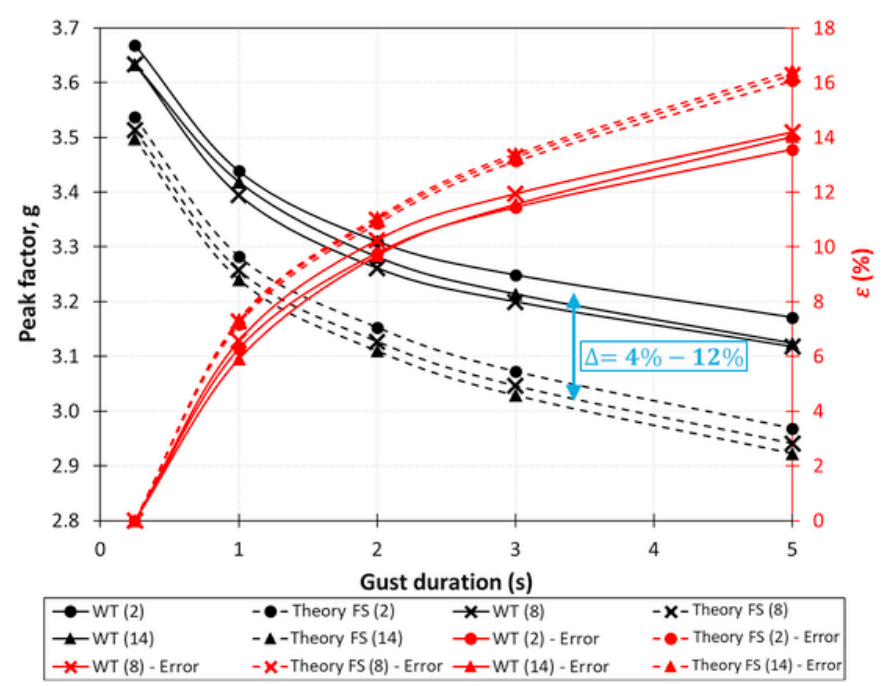

Fig. 4. Comparison of the peak factor values $(g)$ and variations ( $\varepsilon$, Equation (8)) at different gust durations obtained from the WT tests and theoretical approach (FS) for three different turbulence intensities, namely 33\% (Run \#2), 20\% (Run \#8) and 11\% (Run \#14). 


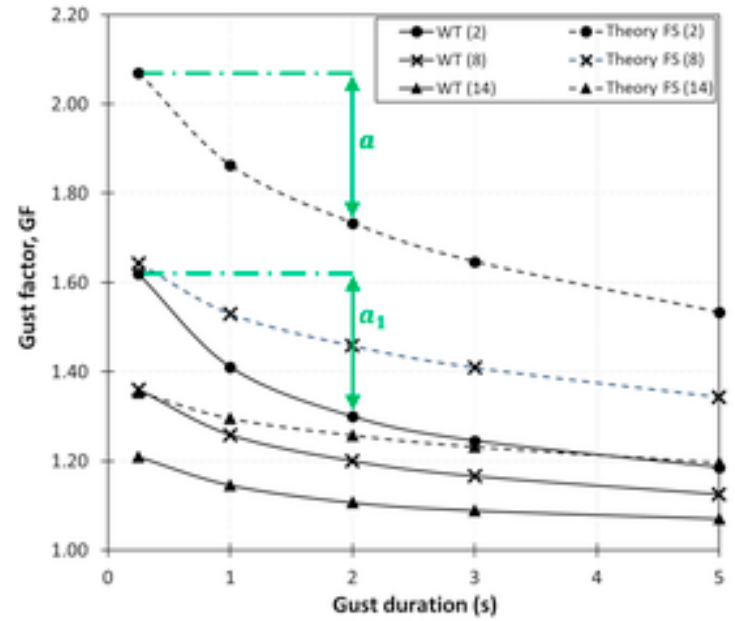

(a)

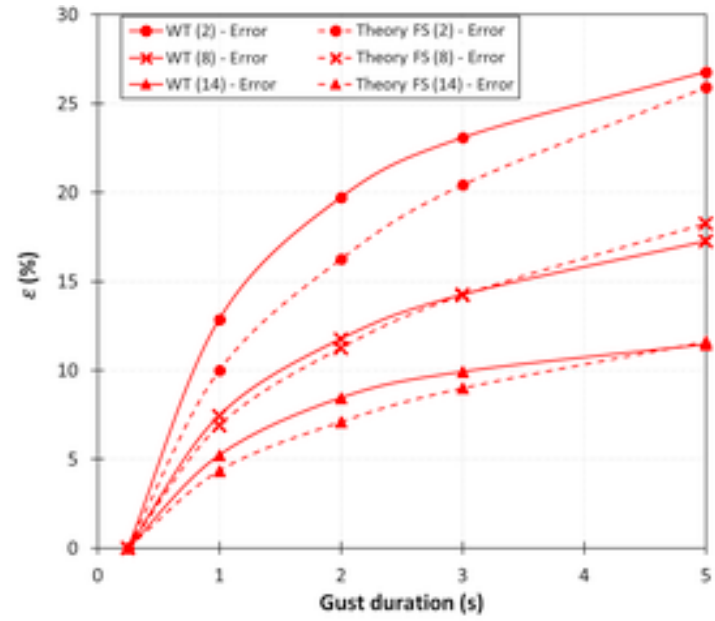

(b)

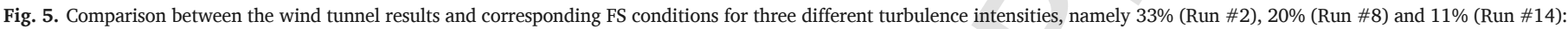
(a) gust factor values (GF); (b) gust factor variations ( $\varepsilon$, Equation (8)) both as functions of gust duration.

It can be seen in Fig. 5(a) that the gust factor decreases from both an increase in the gust duration or a decrease in the turbulence intensity. Thus, as evident in Fig. 5(a) the gust factor has much higher values for the raw measurements (i.e. $4 \mathrm{~Hz}$ output of the anemometer without applying a moving average) compared to the longer gust durations. Based on the definition of the gust factor (Equation (4)), since the mean wind speed does not change with the gust duration, at lower effective gust durations anemometers obviously record higher gust speeds.

To further investigate the change in gust factor with gust duration, the percent reduction in gust factor for each gust duration with respect to the raw unfiltered measurements are shown in Fig. 5(b). The maximum difference between the WT and FS results was observed for the high-turbulence condition (i.e. Run \#2) with a value of $3.5 \%$ for a 2 -s gust duration. For the low- and moderate-turbulence conditions (i.e. Run \#14 and 8, respectively), the difference between the FS and WT results was negligible (less than $0.5 \%$ ). As can be seen, excellent agreement is achieved between the values calculated from the WT measurements and the theoretical FS approach, meaning that the ratios and er-

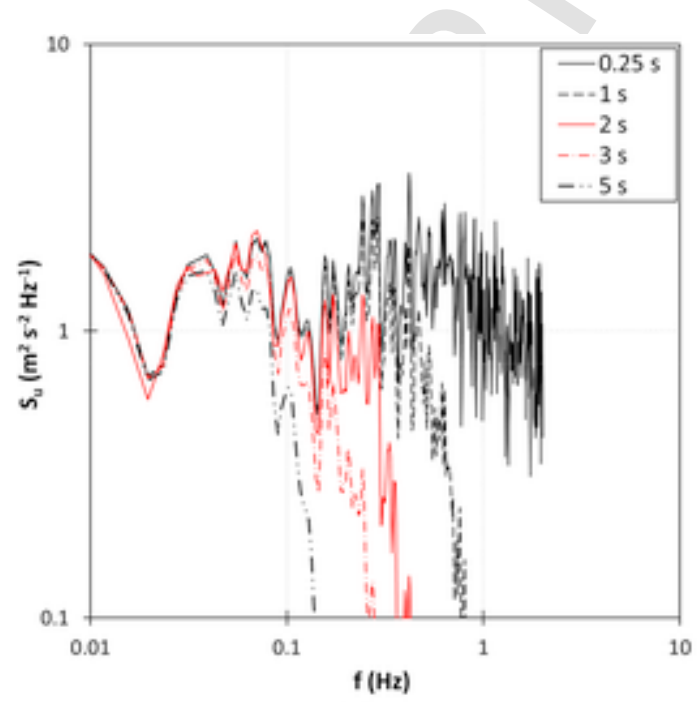

(a) rors found in the present WT experiments can be applied directly to FS measurements.

As can be seen in Fig. 5(b), the differences in gust factor due to changing the moving average duration from 0 to $5 \mathrm{~s}$ vary from $10 \%$ to over $25 \%$ and from $5 \%$ to $12 \%$ under high and low turbulence conditions, respectively. This result demonstrates that the gust factor is highly sensitive to both the gust duration and the turbulence level of the approaching airflow.

From a related point of view, applying a moving average filter reduces the area under the wind spectrum (Fig. 6(a)), which consequently reduces the standard deviation and influences the cycling rate (Equation (6) and (7), respectively). These changes in $\sigma_{u}$ and $v$ cause the peak factor and gust factor to vary with the gust duration. Fig. 6(b) demonstrates how the fluctuations of the recorded wind speeds are smoothed when a moving average filter is applied to the signal. Consequently, all the peaks (for both the maximum and minimum wind speeds) are reduced with an increase in the effective gust duration.

There are a few studies that report gust factor ratios for some specific applications. For example, Holmes and Ginger (2012) and Miller et al. (2013) attempted to find correction factors to con-

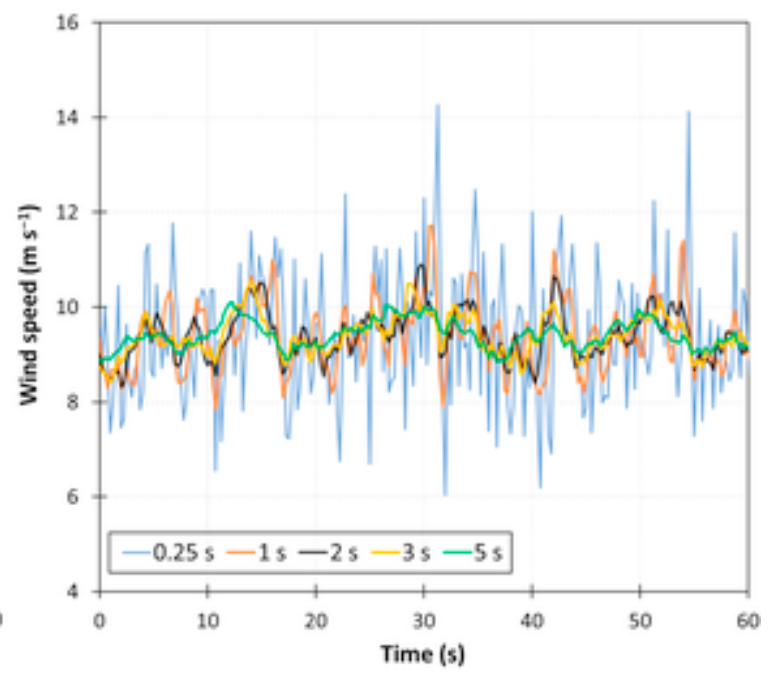

(b)

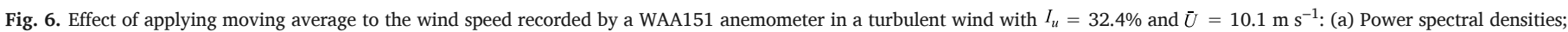
(b) Wind speed time series. 
vert the measurements from the Dines anemometer with an effective gust duration of 0.2-s to equivalent measurements from a heavy-cup Synchrotac 706 anemometer with a 3-s gust duration, and vice versa. They used a similar approach to the theoretical method employed in the current study. Although Holmes and Ginger (2012) and Miller et al. (2013) used different instruments from the present study, their results can be used for comparison purposes. This is due to the fact that the heavy effect of the WMO-recommended 3-s moving average filter suppresses the lighter filtering from the anemometer response characteristics. In addition, the light cup anemometer used in the present study in conjunction with the $4 \mathrm{~Hz}$ sampling frequency has performance that is relatively comparable to that of the 0.2-s gust duration measurements of the Dines anemometer, as demonstrated in Fig. 7. Following the method employed by Kwon and Kareem (2014), Fig. 7 compares normalised wind spectra obtained from the wind-tunnel measurements using the Vaisala cup anemometer, and using the von Karman spectra (i.e. theoretical approach) by utilising the response characteristics (i.e. distance constant) of the anemometer and different moving average durations. As can be seen, the 0.25 -s moving average filter agreed well with the anemometer/recording system. However, the 1- and 3-s moving average filters significantly underestimated the spectrum.

Holmes and Ginger (2012) and Miller et al. (2013) reported gust factor ratios that convert the 3-s Synchrotac gust measurements to equivalent 0.2-s gust measurements of the Dines anemometer, for turbulence intensities of $25 \%, 20 \%, 15 \%$ and $10 \%$. These turbulence intensities broadly correspond to the present wind tunnel runs 5, 8, 11 and 14, respectively. The present results from both the WT experiment and theoretical FS approach, along with those of Holmes and Ginger (2012) and Miller et al. (2013) are shown in Fig. 8. Excellent agreement was achieved between the gust factor ratios obtained from the wind tunnel and from the theory, and those reported by Holmes and Ginger (2012) and Miller et al. (2013). For the low- and moderate turbulence intensities (i.e. $10 \%, 15 \%$ and $20 \%$ ), the difference between the gust factor ratio results (Fig. 8) of the present study and those reported in (Miller et al., 2013; Holmes and Ginger, 2012) is less than $1.5 \%$. The difference becomes slightly larger for the high-turbulence case (i.e. $25 \%$ ) and reaches about $3.5 \%$.

The differences between the theoretical FS approach and the WT results can be attributed to several factors, as outlined below. In addition, the advantages and disadvantages of each method are described.

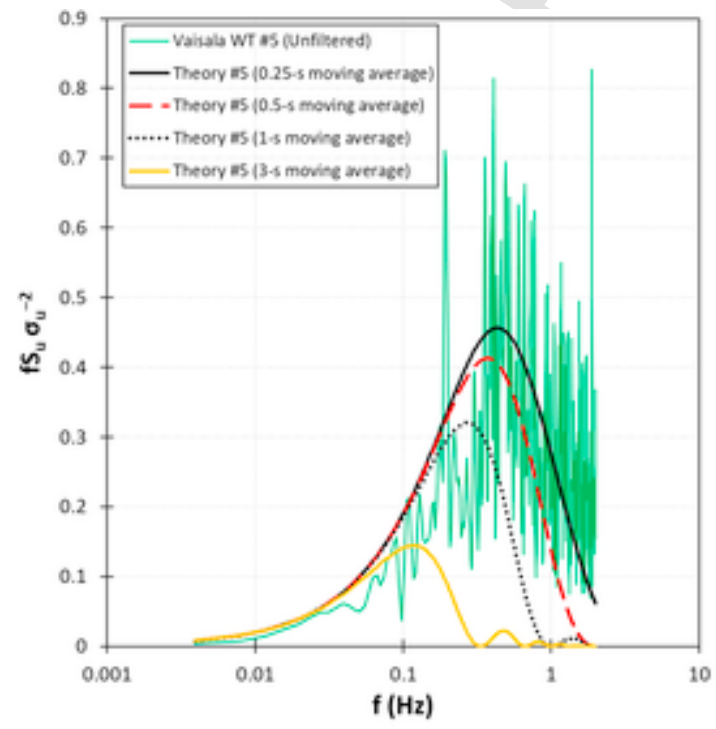

(a)
- In the theoretical FS approach, the response characteristics of the anemometer are not described thoroughly. For instance, the $\left|H_{2}(f)\right|^{2}$ transfer function is not able to take into account the over-speeding issue of cup anemometers (Miller et al., 2013). Over-speeding is one of the most significant and most well-known issues with cup anemometers that introduces errors in the wind speed measurements (Kristensen, 1998; Busch and Kristensen, 1976; Hyson, 1972; Wyngaard, 1981). Over-speeding of a cup anemometer not only depends on the type and response characteristics of the anemometer, but also on the magnitude of the fluctuations of the lateral component of the incoming wind (Miller et al., 2013; Kristensen, 1998) and on the turbulence intensity of the wind, and the shape of the power spectral density (Busch and Kristensen, 1976). Thus, simplifying the real response characteristics of the anemometer in the theoretical approach could influence the results. On the other hand, in WT experiments, the true response characteristics of both the anemometer and the data logger are accounted for automatically by the instrument, along with the turbulence properties of the wind, without any simplification assumptions.

- Compared with the ABL, the replicated turbulence in the WT is at higher frequencies and contains much smaller turbulence integral length scales. However, for the theoretical FS approach, the turbulence length scales corresponding to the FS ABL can be used. It was demonstrated that although the absolute values of the gust factors obtained from the WT flow were lower than those of the ABL (i.e. theory), the trend of gust factor reduction with increase in the gust duration, and most importantly the gust factor ratios (Equation (9)) are comparable in both approaches.

- The wind speed range and the level of the generated turbulence intensity in the WT are limited and are dependent on the available facilities. However, in the theoretical FS approach, any values of meaningful wind speed and turbulence intensity, can be used.

- An alternative approach is to conduct field experiments, as they do not require any assumptions and simplifications in both the anemometer response characteristics and the ABL turbulence. However, in this approach the experiments are less controllable compared to the WT. Field measurements would probably provide the most reliable and accurate results, in terms of comparing different types of anemometers and signal processing methods, when the anemome-

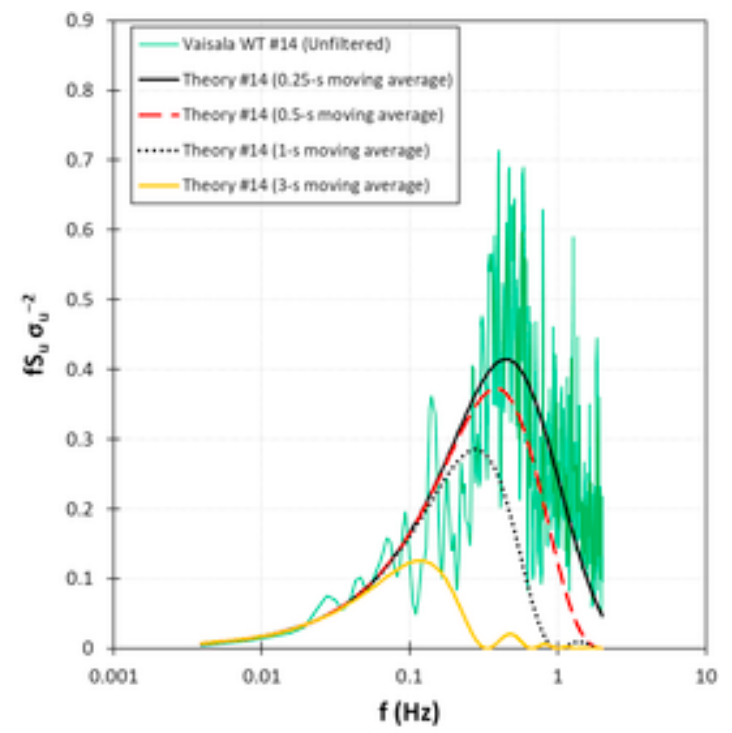

(b)

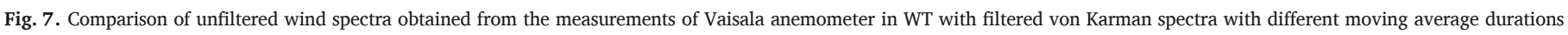
for two cases of: (a) medium (\#5) and (b) low (\#14) turbulence intensities. 


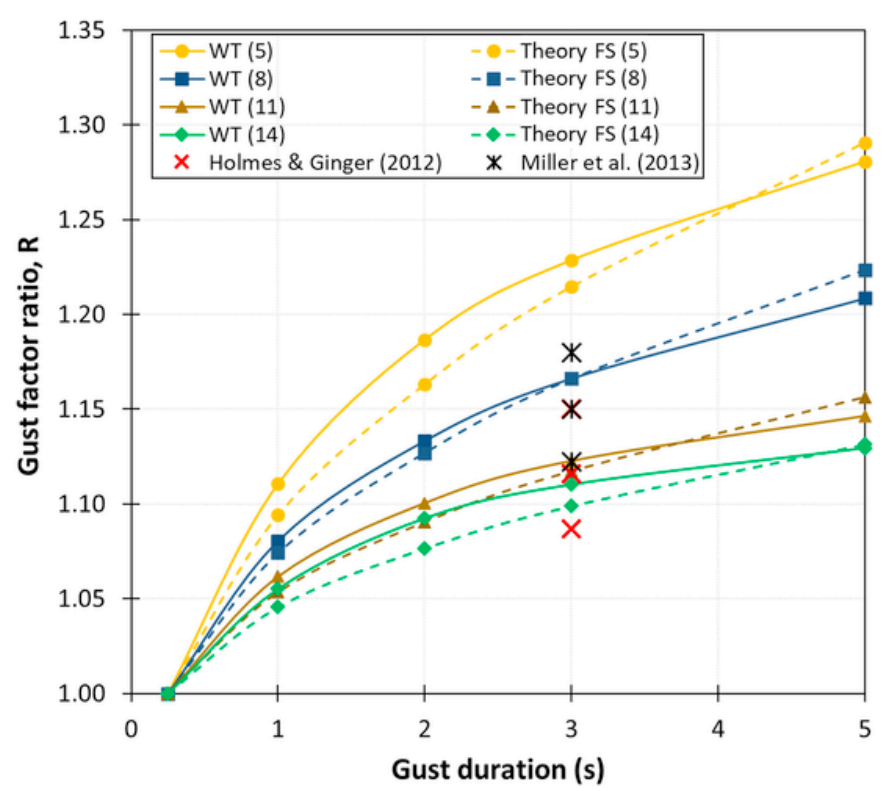

Fig. 8. Comparison between the gust factor ratios (Equation (9)) obtained from WT tests and the theoretical approach (i.e. FS conditions), and those reported by Holmes and Ginger (Holmes and Ginger, 2012) and Miller et al. (Miller et al., 2013).

ters are exposed to the same wind field. As in our previous research (Azorin-Molina et al., 2018), future work will attempt to develop a field intercomparison of the impact of anemometers and moving average filter duration on gust wind speed measurements.

\subsection{Application and example}

The main objective of the present work is to emphasise the effects of gust duration on gust wind speed measurements, and to quantitatively assess the effect of the filtering caused by applying a moving average. In addition, knowing gust factor ratios (Equation (9)) is of great importance and is of much practical use in many research areas, such as the homogenisation of historical gust records of a country, the comparison of gust climatologies of two or more countries where different gust durations have been adopted, the validation of weather prediction models with observed wind speeds at meteorological stations, and so on. These ratios allow gust measurements recorded with a certain moving average duration to be converted to equivalent measurements with particular specified gust durations of interest. Therefore, this section presents and discusses the values of gust factor ratios for several different gust durations, which are being used in several ongoing research programmes. The gust factor ratios (Equation (9)) and errors (Equation (8)) obtained from the WT experiment and the theoretical FS approach for four sets of gust durations at various turbulence intensities are shown in Fig. 9.

In the nearby countries Sweden and Norway, gust speeds are recorded using different gust durations, namely 2- and 3-s, respectively. This difference makes the direct comparison of gust speed observations, or predicted gust speeds using weather prediction models very challenging for the two countries. Therefore, the gust factor values obtained for the 2-s and 3-s gust durations are compared in detail in Fig. 9(a). It is evident from Figs. 4 and 5 that increasing the gust duration from 2-s to 3-s decreases both the gust and peak factors, meaning

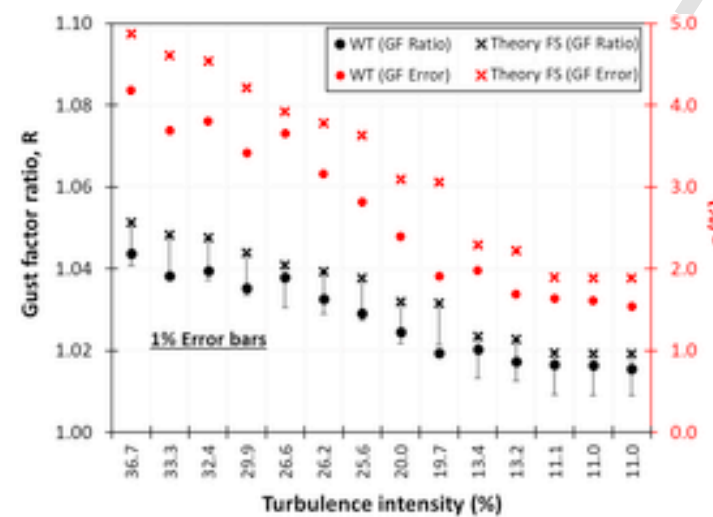

(a)

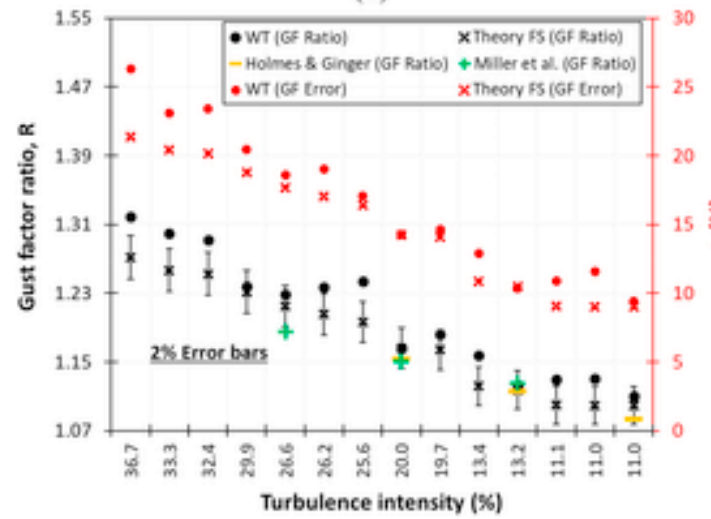

(c)

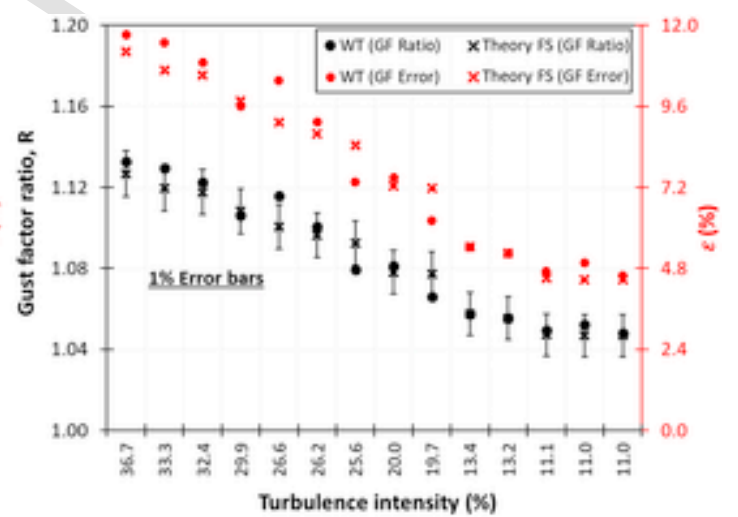

(b)

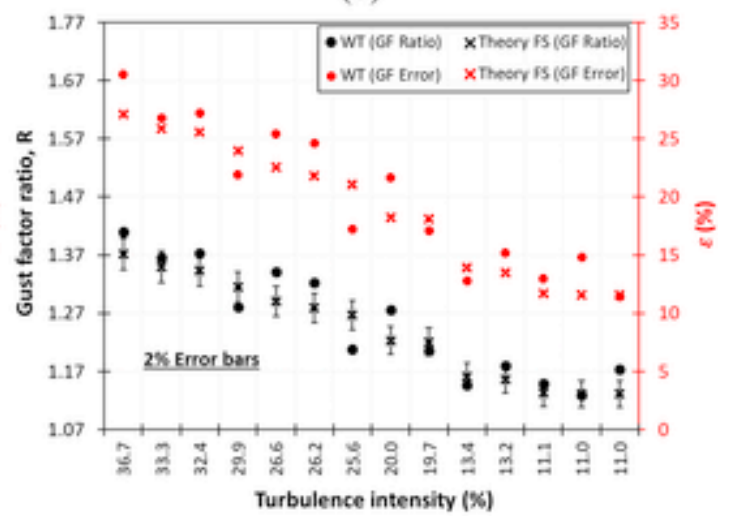

(d)

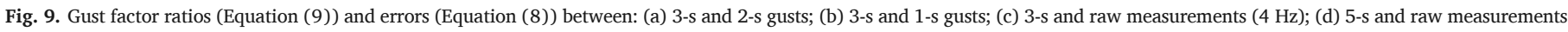
(4 Hz). 
that lower gust wind speeds are recorded when employing 3-s gust duration compared to a shorter 2-s gust durations.

As can be seen in Fig. 9(a), at high turbulence intensities (37\%), the gust factor ratios $(R)$ and errors $(\varepsilon)$ range from 1.033 to 1.044 and $3 \%-4.5 \%$, respectively. As $I_{u}$ reduces to $11 \%, R$ and $\varepsilon$ drop to around 1.016 and $1.5 \%$, respectively. This means that at high turbulence intensities, 3-s gust wind speeds are about $4 \%$ lower than 2-s gust speeds, given the same incoming flow. It is also evident in Fig. 9(a) that the $R$ values obtained from the WT are within $1 \%$ of those calculated from the theory ( $1 \%$ error bars are shown in the figure), and the WT $\varepsilon$ values are only about $0.3 \%-0.6 \%$ less than the theoretical FS results.

Although not shown here, the difference in gust wind speeds (i.e. maximum wind speed) measured by 2-s and 3-s definitions, have a similar trend to the gust factor ratios. At high $I_{u}$, the maximum wind speeds differ by $3 \%-7 \%$ between 3 -s and 2-s gust durations, and at low $I_{u}$, the differences decrease to $1 \%-3 \%$.

Some recent studies on the analysis of historical wind data across New Zealand (Turner et al., 2019; Safaei Pirooz et al., 2018a, 2018b, 2019a, 2019b; Safaei Pirooz and Flay, 2017, 2018) have demonstrated that two of the main factors that have significantly affected the gust wind speed time series recorded in New Zealand were changes in instrumentation and gust duration. These took place during the implementation of the Automatic Weather Stations (AWS) and the adaptation of the WMO - recommended (World Meteorological Orga, 2014) 3-s moving average gust definition in the 1990s.

The heavy Mark II Munro cup anemometer with a chart recorder was the primary wind speed-recording instrument in New Zealand until it was replaced by light Vector A101 and Vaisala WAA151 cup anemometers with digital recorders in the 1990s. Significant differences between the old and new systems, in terms of the response characteristics of the instruments, and observation practice and signal processing methods, considerably affected the historical wind data over the period of the record. Fig. 10, by way of example, shows the discontinuities in the Auckland and Wellington annual maximum gust wind speeds that occurred in the 1990s.

The effective gust duration before the use of digital recording systems was a function of the anemometer response. Holmes et al. (2014) showed that for a cup anemometer, $\tau_{\text {equiv }}$ can be approximated by $2(D / \bar{U})$, and earlier analogue data recorded directly from anemometers generally had an equivalent gust duration of less than $1 \mathrm{~s}$, although, since the 1990s, the WMO-recommended 3-s moving average definition has (rather unfortunately) been applied to the data recorded by meteorological stations across New Zealand. Thus, in Fig. 9(b) the gust factor ratios for converting 3 -s to 1 -s gust measurements, and

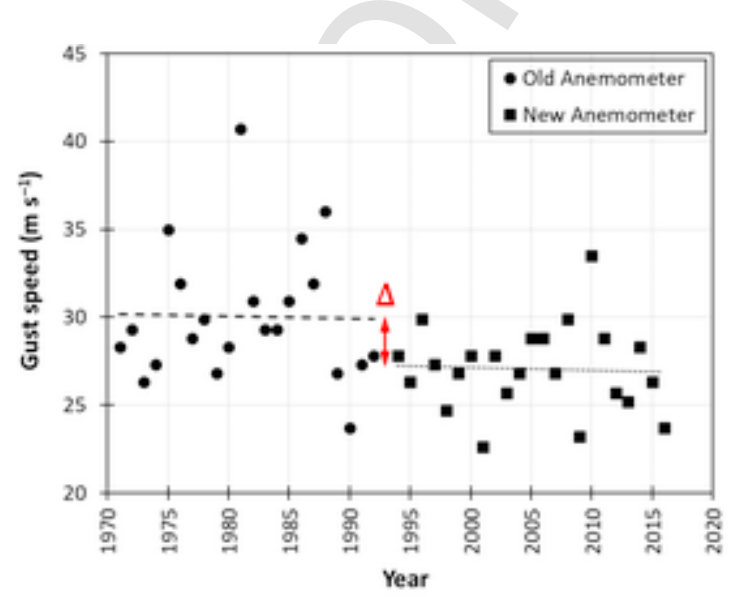

(a) vice versa, are provided. Results such as these have helped homogenise the wind speed time series and to eliminate breakpoints (Fig. 10) in New Zealand wind data records. The value of $R$ varies from 1.130 at high turbulence intensities to 1.047 at low turbulence intensities, which correspond to errors of $11.7 \%$ and $4.5 \%$, respectively. $1 \%$ error bars around the theoretical values shown in Fig. 9 verify that the WT results are within $1 \%$ of the theoretical FS results, or less.

Gust factor ratios to convert 3-s and 5-s gust measurements to $4 \mathrm{~Hz}$ gust measurements are shown in Fig. 9(c) and (d), respectively. In Australia, similar to New Zealand, the wind speed measuring system was changed in the 1990s, in Australia's case, from Dines anemometers to Syncrotech cup anemometers. The former instrument had a short gust duration of about 0.2-s (Holmes and Ginger, 2012), whereas after the 1990s the 3-s moving average gust definition was applied to the recorded data. Holmes and Ginger (2012) and Miller et al. (2013) provide gust factor ratios that convert 0.2-s gust measurements to 3-s measurements, using the random process and linear system theory approach, which are also shown in Fig. 9(c) along with the results of the present study. As can be seen, excellent agreement is achieved between the values reported in the literature and the present WT and theoretical FS results. At high and low turbulence intensities, gust factor ratios of about $1.25-1.30$ and $1.10-1.13$ are required to convert 3 -s gust records to equivalent $4 \mathrm{~Hz}$ raw measurement gust wind speeds, respectively. Also, applying a 3 -s moving average filter results in up to a $25 \%$ and $10 \%$ reduction in the values of gust speeds compared to the $4 \mathrm{~Hz}$ gust speeds at high and low turbulence intensities, respectively.

As the gust duration increases, the gust factor reduces further, and this can be seen in Fig. 9(d), where the gust factor ratios between $4 \mathrm{~Hz}$ raw and 5-s gust speeds are shown. The gust factor ratios (and errors) reach around $1.41(25 \%-30 \%)$ and $1.16(10 \%-15 \%)$ at high and low turbulence intensities, respectively.

As discussed in detail above, the error and gust factor ratio values resulting from applying a moving average filter can be very significant, which, if not taken into account when analysing wind data, can contaminate the subsequent analyses and result in misleading conclusions. The gust factor ratios presented in the current study can be used by researchers from various research fields and industries to homogenise, compare, and study the gust wind speeds.

\section{Conclusions}

Wind-tunnel experiments were conducted to investigate the effects of the effective gust (moving average) durations on measured maximum gust wind speeds, and also to quantify the errors rising from applying a moving average filter to a wind signal. A theoretical ap-

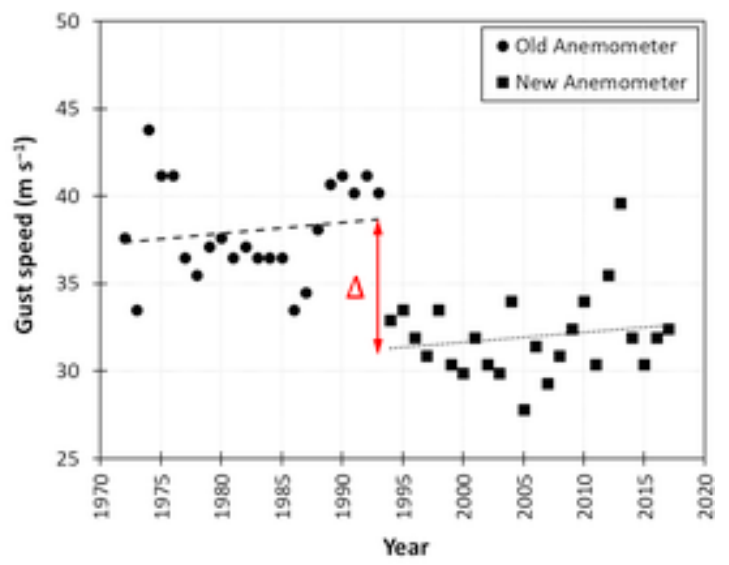

(b)

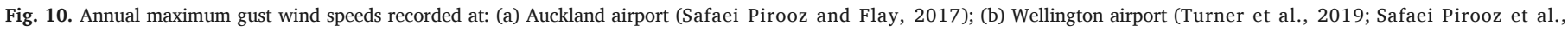
2018a). 
proach, which uses the properties of the full-scale wind speed in the atmospheric boundary layer, was also employed, and its results were compared with those from the wind tunnel. Excellent agreement was achieved between the differences and gust factor ratios computed from the wind-tunnel tests, the theoretical approach, and values reported in the literature. To summarise, the major findings of this experimental study are:

1. The results show that increasing the effective gust duration reduces both the gust and peak factors, resulting in an underestimation of maximum gust wind speeds and an overestimation of minimum gust wind speeds.

2. The maximum difference between gust factors obtained for high (e.g. 3-s to 5-s) and low (raw, unfiltered measurements) gust durations reached values of $25 \%-30 \%$ for the high turbulence conditions, and up to $5 \%-10 \%$ for low turbulence intensities.

3. Gust factor ratios, an important parameter that allow the measurements from a specific gust duration to be converted to other gust durations of interest, are reported for various gust durations as a function of turbulence intensity.

4. The differences and gust factor ratios computed in this study can be applied directly to full-scale measurements, and can be used in several research areas, including analysing and homogenisation of historical wind speed time series, comparing gust climatologies of countries where different gust durations have been adopted, and so on. These factors clearly play an essential role in meteorological, climatological and wind engineering studies.

The results of the present study are being used in several ongoing research projects by the authors, such as the assessment of the predictions of a weather forecast model in comparison with observed wind speeds over Sweden and Norway; the prediction of New Zealand design wind speeds, and long-term trends in magnitudes and frequencies of extreme wind speeds.

\section{CRediT authorship contribution statement}

Amir Ali Safaei Pirooz: Conceptualization, Methodology, Validation, Formal analysis, Investigation, Data curation, Writing - original draft, Visualization, Writing - review \& editing, Software. Richard G.J. Flay: Conceptualization, Supervision, Writing - review \& editing, Methodology, Funding acquisition, Project administration. Lorenzo Minola: Conceptualization, Writing - review \& editing. Cesar Azorin-Molina: Conceptualization, Writing - review \& editing, Funding acquisition. Deliang Chen: Writing - review \& editing, Funding acquisition.

\section{CRediT authorship contribution statement}

Amir Ali Safaei Pirooz: Conceptualization, Methodology, Validation, Formal analysis, Investigation, Data curation, Writing - original draft, Visualization, Writing - review \& editing, Software. Richard G.J. Flay: Conceptualization, Supervision, Writing - review \& editing, Methodology, Funding acquisition, Project administration. Lorenzo Minola: Conceptualization, Writing - review \& editing. Cesar Azorin-Molina: Conceptualization, Writing - review \& editing, Funding acquisition. Deliang Chen: Writing - review \& editing, Funding acquisition.

\section{Declaration of competing interest}

The authors declare that they have no known competing financial interests or personal relationships that could have appeared to influence the work reported in this paper

\section{Acknowledgments}

The authors are grateful to the New Zealand MetService and NIWA for providing the anemometers for the tests. The study is partly funded by three projects: (i) New Zealand Ministry of Business, Innovation and Employment, through "New Zealand Natural Hazards Platform", contract number C05X0907; (ii) Swedish Research Council, "Detection and attribution of changes in extreme wind gusts over land" (2017-03780); and (iii) Spanish Ministry of Science, Innovation and Universities, "Evaluación y atribución de la variabilidad de la velocidad media y las rachas máximas de viento: causas del fenómeno "stilling" (RTI2018-095749-A-I00). Cesar Azorin-Molina was supported by Ramon y Cajal Fellowship (RYC-2017-22830). The authors also would like to thank Dr. Yin Fai Li, Wind Tunnel Engineer at the University of Auckland, for the fruitful discussions and helpful suggestions regarding the wind-tunnel experiments.

\section{References}

[/S11702 and Australia/N, 2011] AS/NZS1170.2, Australia/New Zealand Standard, Structural Design Actions. Part 2: Wind Actions, Jointly Published by Standards Australia, International Ltd and Standards New Zealand, 2011.

[7-05 and Minimum Design, 2006] ASCE7-05, Minimum Design Loads for Buildings and Other Structures, American Society of Civil Engineers, Reston, Virginia, 2006.

[7-95 and Minimum Design, 1995] ASCE7-95, Minimum Design Loads for Buildings and Other Structures, American Society of Civil Engineers, Reston, Virginia, 1995.

[Abiven et al, 2011] C Abiven, J M L M Palma, O Brady, High-frequency field measurements and time-dependent computational modelling for wind turbine siting, J. Wind Eng. Ind. Aerod. 99 (2011) 123-129, doi:10.1016/j.jweia.2010.12.006.

[Azorin-Molina et al, 2014] C Azorin-Molina, S M Vicente-Serrano, T R Mcvicar, S Jerez, A Sanchez-Lorenzo, J- López-Moreno, J Revuelto, R M Trigo, $\mathrm{J}$ A Lopez-Bustins, F Espírito-Santo, Homogenization and assessment of observed near-surface wind speed trends over Spain and Portugal, 1961-2011, J. Clim. 27 (2014) 3692-3712, doi:10.1175/JCLI-D-13-00652.1.

[Azorin-Molina et al, 2017] C Azorin-Molina, S M Vicente-Serrano, T R McVicar, J Revuelto, S Jerez, J López-Moreno, Assessing the impact of measurement time interval when calculating wind speed means and trends under the stilling phenomenon, Int. J. Climatol. 37 (2017) 480-492, doi:10.1002/joc.4720.

[Azorin-Molina et al, 2018] C Azorin-Molina, J Asin, T R McVicar, L Minola, J I Lopez-Moreno, S M Vicente-Serrano, D Chen, Evaluating anemometer drift: a statistical approach to correct biases in wind speed measurement, Atmos. Res. 203 (2018) 175-188, doi:10.1016/j.atmosres.2017.12.010.

[Azorin-Molina et al, 2019] C Azorin-Molina, J A Guijarro, T R McVicar, B C Trewin, A J Frost, D Chen, An approach to homogenize daily peak wind gusts: an application to the Australian series, Int. J. Climatol. 39 (2019) 2260-2277, doi:10.1002/joc.5949.

[Azorin-Molina et al, 2016] C Azorin-Molina, J Guijarro, T R McVicar, S M Vicente-Serrano, D Chen, S Jerez, F Espírito-Santo, Trends of daily peak wind gusts in Spain and Portugal, 1961-2014, J. Geophys. Res. Atmos. 121 (2016) 1059-1078, doi:10.1002/ 2015JD024485.

[Balderrama et al, 2012] J A Balderrama, F J Masters, K R Gurley, Peak factor estimation in hurricane surface winds, J. Wind Eng. Ind. Aerod. 102 (2012) 1-13, doi:10.1016/j.jweia.2011.12.003.

[Bégin-Drolet et al, 2011] A Bégin-Drolet, J Ruel, J Lemay, Off-axis characterization of ice-free anemometers, J. Wind Eng. Ind. Aerod. 99 (2011) 825-832, doi:10.1016/j.jweia.2011.05.007.

[Bégin-Drolet et al, 2012] A Bégin-Drolet, J Ruel, J Lemay, G Giroux, Commissioning of a new ice-free anemometer: 2011 Field tests at WEICan, Meas. J. Int. Meas. Confed. 45 (2012) 2029-2040, doi:10.1016/ j.measurement.2012.05.010.

[Beljaars, 1987] A C M Beljaars, The influence of sampling and filtering on measured wind gusts, J. Atmos. Ocean. Technol. 4 (1987) 613-626, doi:10.1175/ 1520-0426(1987)0042.0.CO;2.

[Busch and Kristensen, 1976] N E Busch, L Kristensen, Cup anemometer overspeeding, J. Appl. Meteorol. 15 (1976) 1328-1332.

[Cao et al, 2015] S Cao, Y Tamura, N Kikuchi, M Saito, I Nakayama, Y Matsuzaki, A case study of gust factor of a strong typhoon, J. Wind Eng. Ind. Aerod. 138 (2015) 52-60, doi:10.1016/j.jweia.2014.12.012.

[Cook, 1985] N J Cook, The Designer's Guide to Wind Loading of Building Structures Part 1, first ed., Butterworths, The University Press, Cambridge, UK, 1985. [D5096-02 and Standard T, 2017] ASTM D5096-02, Standard Test Method for Determining the Performance of a Cup Anemometer or Propeller Anemometer, American Society 
for Testing and Materials, West Conshohocken, PA, United States, 2017.

[Davenport, 1964] A G Davenport, Note on the distribution of the largest value of random function with application to gust loading, Proceeding of the Institutions of Civil Engineers, 28, 1964, pp. 187-196.

[Deaves and Harris, 1978] D M Deaves, R I Harris, A mathematical model of the structure of strong winds, CIRIA Rep. 76 (1978).

[Durst, 1960] C S Durst, Wind speeds over short periods of time, Meteorol. Mag. 89 (1960) 181-186.

[Farrugia and Sant, 2013] R N Farrugia, T Sant, Modelling wind speeds for cup anemometers mounted on opposite sides of a lattice tower: a case study, J. Wind Eng. Ind. Aerod. 115 (2013) 173-183, doi:10.1016/j.jweia.2012.11.006.

[Flay et al, 2019] R G J Flay, A B King, M Revell, P Carpenter, R Turner, P Cenek, A A Safaei Pirooz, Wind speed measurements and predictions over belmont hill, Wellington, New Zealand, J. Wind Eng. Ind. Aerod. 195 (2019) 104018, doi:10.1016/j.jweia.2019.104018.

[Giannoulis et al, 2010] A Giannoulis, T Mistriotis, D Briassoulis, Experimental and numerical investigation of the airflow around a raised permeable panel, J. Wind Eng. Ind. Aerod. 98 (2010) 808-817, doi:10.1016/j.jweia.2010.07.005.

[He et al, 2016] Y C He, P W Chan, Q S Li, Observations of vertical wind profiles of tropical cyclones at coastal areas, J. Wind Eng. Ind. Aerod. 152 (2016) 1-14, doi:10.1016/j.jweia.2016.01.009.

[Holmes, 2015] J D Holmes, Wind Loading of Structures, third ed., Taylor \& Francis Group, 2015.

[Holmes and Ginger, 2012] J D Holmes, J D Ginger, The gust wind speed duration in AS/NZS 1170.2, Aust. J. Struct. Eng. 13 (2012) 207-217.

[Holmes et al, 2014] J D Holmes, A C Allsop, J D Ginger, Gust durations, gust factors and gust response factors in wind codes and standards, Wind Struct. 19 (2014) 339-352.

[Hyson, 1972] P Hyson, Cup anemometer response to fluctuating wind speeds, J. Appl. Meteorol. 11 (1972) 843-848.

[Izumi and Barad, 1970] Y Izumi, M L Barad, Wind speeds as measured by cup and sonic anemometers and influenced by tower structure, J. Appl. Met. 9 (1970) 851-856.

[Kaimal and Wyngaard, 1990] J C Kaimal, J C Wyngaard, The Kansas and Minnesota experiments, Boundary-Layer Meteorol. 50 (1990) 31-47, doi:10.1007/BF00120517.

[Krayer and Marshall, 1992] W R Krayer, R D Marshall, Gust factors applied to hurricane winds, Bull. Am. Meteorol. Soc. 73 (1992) 613-618, doi:10.1175/1520-0477(1992)0732.0.CO;2

[Kristensen, 1998] L Kristensen, Cup anemometer behavior in turbulent environments, J. Atmos. Ocean. Technol. 15 (1998) 5-17.

[Kwon and Kareem, 2014] D K Kwon, A Kareem, Revisiting gust averaging time and gust effect factor in ASCE 7, J. Struct. Eng. 140 (2014), doi:10.1061/(ASCE)ST.1943-541X.0001102.

[Lubitz and Michalak, 2018] W D Lubitz, A Michalak, Experimental and theoretical investigation of tower shadow impacts on anemomete measurements, J. Wind Eng. Ind. Aerod. 176 (2018) 112-119, doi:10.1016/j.jweia.2018.03.012.

[Maribo Pedersen et al, 1992] B Maribo Pedersen, K S Hansen, S Øye, M Brinch, O Febian, Some experimental investigations on the influence of the mounting arrangements on the accuracy of cup-anemometer measurements, J. Wind Eng. Ind. Aerod. 39 (1992) 373-383, doi:10.1016/0167-6105(92)90561-N.

[Masters et al, 2010] F J Masters, P J Vickery, P Bacon, E N Rappaport, Towards objective, standardized, intensity estimates from surface wind speed observations, Bull. Am. Meteorol. Soc. 91 (2010) 1665-1681, doi:10.1175/2010BAMS2942.1.

[McVicar et al, 2012] T R McVicar, M L Roderick, R J Donohue, L T Li, T G Van Niel, A Thomas, J Grieser, D Jhajharia, Y Himri, N M Mahowald, A V Mescherskaya, A C Kruger, S Rehman, Y Dinpashoh, Global review and synthesis of trends in observed terrestrial near-surface wind speeds: implications for evaporation, J. Hydrol. 416-417 (2012) 182-205, doi:10.1016/j.jhydrol.2011.10.024.

[Miller, 2007] C Miller, Defining the effective duration of a gust, Proc. 12th Intl. Conf Wind Eng. (ICWE12), Intl. Asoc. For Wind Eng. Cairns, Australia, July 2-6, 2007, pp. 759-766.

[Miller et al, 2013] C Miller, J Holmes, D Henderson, J Ginger, M Morrison, The response of the Dines anemometer to gusts and comparisons with cup anemometers, J. Atmos. Ocean. Technol. 30 (2013) 1320-1336, doi:10.1175/JTECH-D-12-00109.1.

[Murakami and Fujii, 1983] S Murakami, K Fujii, Turbulence characteristics of wind flow at ground level in built-up area, J. Wind Eng. Ind. Aerod. 15 (1983) 133-144, doi:10.1016/ 0167-6105(83)90184-8.

[Ohba et al, 1988] M Ohba, N Kobayashi, S Murakami, Study on the assessment of environmental wind conditions at ground level in a built-up area based on long-term measurements using portable 3-cup anemometers, J. Wind Eng. Ind. Aerod. 28 (1988) 129-138, doi:10.1016/0167-6105(88)90109-2.

[Orlando et al, 2011] S Orlando, A Bale, D A Johnson, Experimental study of the effect of tower shadow on anemometer readings, J. Wind Eng. Ind. Aerod. 99 (2011) 1-6, doi:10.1016/j.jweia.2010.10.002.
[Palma et al, 2008] J M L M Palma, F A Castro, L F Ribeiro, A H Rodrigues, A P Pinto, Linear and nonlinear models in wind resource assessment and wind turbine micro-siting in complex terrain, J. Wind Eng. Ind. Aerod. 96 (2008) 2308-2326, doi:10.1016/j.jweia.2008.03.012.

[Pindado et al, 2012] S Pindado, A Barrero-Gil, A Sanz, Cup anemometers' loss of performance due to ageing processes, and its effect on annual energy production (AEP) estimates, Energies 5 (2012) 1664-1685, doi:10.3390/en5051664.

[Powell et al, 1996] M D Powell, S H Houston, T A Reinhold, Hurricane Andrew's landfall in South Florida. Part I: standardizing measurements for documentation of surface wind fields, Weather Forecast. 11 (1996) 304-328.

[Ramos-Cenzano et al, 2019] A Ramos-Cenzano, M Ogueta-Gutierrez, S Pindado, On the output frequency measurement within cup anemometer calibrations, Measurement 136 (2019) 718-723, doi:10.1016/j.measurement.2019.01.015.

[Safaei Pirooz and Flay, 2017] A A Safaei Pirooz, R G J Flay, Preliminary extreme wind speed estimates for the Auckland region, 9th Asia-Pacific Conference on Wind Engineering, 3-7 December, 2017, pp. 1-4 Auckland, New Zealand, doi:10.17608/ k6.auckland.5630917.v1.

[Safaei Pirooz and Flay, 2018] A A Safaei Pirooz, R G J Flay, Response characteristics of anemometers used in New Zealand, The 19th Australasian Wind Engineering Society Workshop, April 4-6, Torquay, Victoria, 2018

[Safaei Pirooz et al, 2018a] A A Safaei Pirooz, R G J Flay, R Turner, Effects of site relocation and instrument type on recorded wind data characteristics at Wellington Airport, 19th Australasian Wind Engineering Society Workshop, Torquay, Victoria, 2018.

[Safaei Pirooz et al, 2018b] A A Safaei Pirooz, R G J Flay, C Azorin-Molina, Homogenisation of Daily Wind Gusts Recorded at Auckland and Wellington Airports during 1972 - 2017, European Geosciences Union General Assembly 2018, (EGU 2018), Vienna, Austria, 2018, doi:10.13140/RG.2.2.28072.67842.

[Safaei Pirooz et al, 2019a] A A Safaei Pirooz, R G J Flay, R Turner, New Zealand design wind speeds, The 15th International Conference on Wind Engineering, 1-6 September, Beijing, China, 2019.

[Safaei Pirooz et al, 2019b] A A Safaei Pirooz, R G J Flay, R Turner, C Azorin-Molina, Effects of climate change on New Zealand design wind speeds, National Emergency Response 32 (2019) 14-20.

[Sanada et al, 1980] S Sanada, Y Iwasa, M Yoshida, Full-scale measurement of environmental wind in the Shinjuku new metropolitan center, J. Wind Eng. Ind. Aerod. 6 (1980) 291-309, doi:10.1016/ 0167-6105(80)90007-0.

[Shu et al, 2015] Z R Shu, Q S Li, Y C He, P W Chan, Gust factors for tropical cyclone, monsoon and thunderstorm winds, J. Wind Eng. Ind. Aerod. 142 (2015) 1-14, doi:10.1016/j.jweia.2015.02.003.

[Shu et al, 2017] Z R Shu, Q S Li, Y C He, P W Chan, Vertical wind profiles for typhoon, monsoon and thunderstorm winds, J. Wind Eng. Ind. Aerod. 168 (2017) 190-199, doi:10.1016/j.jweia.2017.06.004.

[Sparks, 1997] W Sparks, The gust response of Mk IV wind systems Technical Report No. 12 U.K. Met Office, Exeter, U.K., 1997.

[Tan et al, 2016] L Tan, W Zhang, K Bian, Z An, R Zu, J Qu, Numerical simulation of three-dimensional wind flow patterns over a star dune, J. Wind Eng. Ind. Aerod. 159 (2016) 1-8, doi:10.1016/j.jweia.2016.10.005.

[Turner et al, 2019] R Turner, A A Safaei Pirooz, R G J Flay, S Moore, M Revell, Use of high-resolution numerical models and statistical approaches to understand New Zealand historical wind speed and gust climatologies, J. Appl. Meteorol. Climatol. 58 (2019) 1195-1218, doi:10.1175/JAMC-D-18-0347.1.

[Verkaik, 2000] J W Verkaik, Evaluation of two gustiness models for exposure correction calculations, J. Appl. Meteorol. 39 (2000) 1613-1626, doi:10.1175/ 1520-0450(2000)0392.0.CO;2.

[Wieringa, 1973] J Wieringa, Gust factors over open water and built-up country, Boundary-Layer Meteorol. 3 (1973) 424-441, doi:10.1007/ BF01034986

[Wieringa, 1976] J Wieringa, An objective exposure correction method for average wind speeds measured at a sheltered location, Q. J. R. Meteorol. Soc. 102 (1976) 241-253, doi:10.1002/qj.49710243119.

[Wills, 1992] J A B Wills, Offshore wind structure measurements at the West Sole gas platform, J. Wind Eng. Ind. Aerod. 44 (1992) 2465-2473, doi:10.1016/ 0167-6105(92)90038-C

[World Meteorological Orga, 2014] World Meteorological Organisation, Guide to Meteorological Instruments and Methods of Observations, eighth ed., WMO, Geneva, Switzerland, 2014.

[Wyngaard, 1981] J C Wyngaard, Cup, propeller, vane, and sonic anemometers in turbulence research, Annu. Rev. Fluid Mech. 13 (1981) 399-423.

[Yoshie et al, 2007] R Yoshie, A Mochida, Y Tominaga, H Kataoka, K Harimoto, T Nozu, T Shirasawa, Cooperative project for CFD prediction of pedestrian wind environment in the Architectural Institute of Japan, J. Wind Eng. Ind. Aerod. 95 (2007) 1551-1578, doi:10.1016/ j.jweia.2007.02.023. 